\title{
Estudio de opiniones sobre el desempeño económico: Evidencia para los países de América Latina y el Caribe
}

Martin Llada

Tesis de Maestría

Maestría en Economía

Facultad de Ciencias Económicas - Universidad Nacional de La Plata

Director: José Daniel Aromí

Octubre - 2019 


\title{
Estudio de opiniones sobre el desempeño económico: Evidencia para los países de América Latina y el Caribe
}

\author{
Martín Llada*
}

\begin{abstract}
Resumen
Este trabajo estudia asociaciones entre las opiniones sobre desempeño económico y los flujos de información económica. Las opiniones de los individuos, son extraídas de encuestas realizadas en 18 países de América Latina y el Caribe para el periodo 1995-2016. Los flujos de información están relacionados con variaciones en la tasa de crecimiento, los saldos en cuenta corriente y medidas del tono en las noticias en la prensa. Se encuentra asociaciones estadística y económicamente significativas entre el arribo de información referida a estos indicadores económicos y la medida de opinión pública propuesta. En particular, un incremento de un desvío estándar en el indicador de aceleración de la tasa de crecimiento, en promedio, está asociado a un incremento de 0.26 desviaciones estándares en la medida de opinión referida a las expectativas de los individuos. Sin embargo, la proporción de la variabilidad de las opiniones explicada por los modelos propuestos, es relativamente baja. Adicionalmente, se observa que las expectativas sobre desempeño futuro son informativas sobre opiniones que se reportan posteriormente. La evidencia es consistente con instancias de sub-reacción y sobre-reacción de las expectativas. Los resultados no se modifican cuando se controla por efectos de las preferencias políticas e información sociodemográfica de los individuos.
\end{abstract}

Códigos JEL: E7, E71

Palabras clave: opiniones, expectativas, sentimiento.

\footnotetext{
"Este trabajo se constituye mi tesis de Maestría en Economía de la Facultad de Ciencias Económicas de la Universidad de La Plata (FCE-UNLP), dirigida por José Daniel Aromí, a quien agradezco su enseñanzas, su apoyo y sobre todo su paciencia. Agradezco también los valiosos comentarios de los participantes del seminario de avance de tesis. Cualquier error del presente trabajo es de mi entera responsabilidad.

** Universidad de Buenos Aires. Facultad de Ciencias Económicas. Buenos Aires, Argentina. CONICET Universidad de Buenos Aires. Instituto Interdisciplinario de Economía Política de Buenos Aires. Buenos Aires, Argentina. Email: Iladamartin@gmail.com
} 


\section{Introducción}

Comprender cómo los individuos forman expectativas sobre variables macroeconómicas permite entender sus comportamientos y la trayectoria de agregados macroeconómicos. En este sentido, las creencias de los individuos respecto a la situación actual y al desempeño económico futuro tendrán influencia sobre su comportamiento (consumo, ahorro, inversión, stock de deuda) y, consecuentemente, sobre la dinámica macroeconómica. ${ }^{1}$

Bajo este marco se pretende estudiar cómo los individuos forman sus opiniones ${ }^{2}$ y cómo estas varían ante el arribo de información económica de interés. ${ }^{3}$ Particularmente, se pretende dar respuesta a los siguientes interrogantes: ¿Existen vínculos fuertes entre opiniones e indicadores tradicionales de desempeño económico? ¿Cuál es la medida en que las expectativas reportadas proveen información sobre evaluaciones futuras? Los individuos al formular sus expectativas, ¿utilizan toda la información disponible de manera eficiente? Este trabajo, por lo tanto, pretende arrojar luz sobre los procesos de formación de opiniones.

En pos de atender el proceso de formación de opiniones, se utilizan las encuestas de opinión pública recolectada por la Corporación Latinobarómetro. A partir de estas, se obtienen las expectativas y las evaluaciones de desempeño económico de los individuos de 18 países de América Latina y el Caribe para el período 1995-2016.

A través de diversos ejercicios estadísticos se intenta caracterizar las expectativas y las evaluaciones de desempeño económico de los individuos. En primer lugar, se describe la forma en que estas opiniones están asociadas al arribo de información referida a ciertos indicadores económicos de interés, como son aceleraciones del crecimiento, saldo en cuenta corriente o medidas del tono en la prensa. En este sentido, el resultado esperado es hallar una asociación positiva. En segundo lugar, se evalúa la medida en que las expectativas expresadas por los individuos, al momento de ser encuestados, contienen información sobre las evaluaciones futuras del desempeño económico que estos realizaran. Más específicamente, se proponen modelos simples de predicción de opiniones. En base a estos modelos, se analiza si la información económica preexistente al momento en que se reportan las expectativas, contiene información que va mas allá de lo que comunican dichas expectativas. Un resultado positivo es consistente con ineficiencias en el proceso de formación de expectativas e individuos que no incorporan completamente la información disponible en sus expectativas.

Para evaluar la forma en que los individuos forman sus opiniones sobre el desempeño

\footnotetext{
${ }^{1}$ Ver, por ejemplo, Souleles (2004), Brown y Taylor (2006), Leduc y Sill (2010), Lanzilotta (2015) y Gennaioli, Ma y Shleifer (2015).

${ }^{2}$ En este trabajo se entiende por opiniones a creencias respecto al desempeño económico futuro (expectativas) y creencias respecto al desempeño económico corriente (evaluaciones de la situación actual).

${ }^{3}$ En este trabajo, se entiende el arribo de información económica de interés como la llegada de nuevos datos económicos. Además, este trabajo se concentrará en el contenido de dichos flujos de información, sin considerar los medios a través de los cuales la información arriba a las personas. Respecto a esto último, múltiples trabajos se concentran en las fuentes de dichos flujos de información, las cuales pueden ser múltiple: medios de comunicación, televisión, redes sociales y otras formas de aprendizaje social (Carroll (2003a, 2003b), Lamla 2008, Golub y Jackson 2010).
} 
económico en base a información sobre la economía, se consideran tres variables que tienen por objetivo capturar los flujos de información. La primera, refleja información sobre cambios en el crecimiento económico. La segunda, captura el saldo del balance de cuenta corriente como porcentaje del PBI, un indicador de vulnerabilidad o fortaleza económica. La tercera variable, corresponde a las opiniones predominantes sobre la economía, las cuales, se aproximan a través de un indicador que explota grandes muestras de texto de la prensa económica mundial.

Este estudio muestra, mediante dos ejercicios estadísticos independientes, una asociación económica y estadísticamente significativas entre los flujos de información y las opiniones sobre el desempeño económico. En primer lugar, se estudian las relaciones entre las opiniones de los individuos respecto al desempeño económico actual y dichos flujos de información. En este caso, un incremento de un desvío estándar en cierto indicador se asocia a un aumento entre 0.14 y 0.44 desviaciones estándares en la medida de opiniones sobre el desempeño económico corriente. En segundo lugar, se evalúa la asociación entre estos indicadores económicos y las opiniones respecto al desempeño económico futuro. Los resultados reportados en este trabajo permiten inferir que una variación de un desvío estándar en alguno de los indicadores, se asocia a un incremento en la medida de opiniones sobre desempeño económico futuro del orden de 0.15 a 0.26 desviaciones estándares. Sin embargo, aunque se encuentra asociaciones estadísticamente significativas entre opiniones y flujos de información, ambos modelos tienen poca capacidad de explicar la variabilidad de las opiniones reportadas por los individuos, lo cual se desprende de observar el $R^{2}$ - ajustado de cada modelo: $-1 \%$ y $19 \%$, respectivamente.

Adicionalmente, a partir de un modelo simple de predicción de evaluaciones de desempeño, se evidencia que las expectativas formuladas por los agentes contribuyen a anticipar cómo estos evaluarán el desempeño económico. En particular, se encuentra que un aumento de un desvío estándar en el indicador de expectativas anticipa, en promedio, un aumento de 0.39 desvíos estándares en el indicador de evaluación de la situación económica en el siguiente año. Este resultado es consistente con lo esperado. Sin embargo, se encuentra que, al momento en que se reportan las expectativas, ciertos flujos preexistentes contienen información relevante sobre las evaluaciones futuras que va más allá de lo que explican las expectativas. Específicamente, los flujos de información asociados a aceleraciones en la tasa de crecimiento, el saldo en cuenta corriente y el indicador de opiniones en la prensa, tienen capacidad predictiva sobre las evaluaciones futuras. Esto revela la existencia de ineficiencias en el proceso de formación de expectativas. Por un lado, existe información que no fue capturada por este proceso. Una posible interpretación para estos resultados, se asocia con la presencia de individuos que poseen recursos cognitivos limitados, quienes no incorporan toda la información disponible y, de esta manera, sub-reaccionan a flujos entrantes de información. Por otro lado, se encuentra evidencia de respuestas individuales exageradas al momento de formular sus expectativas, asociadas al indicador de opiniones en la prensa. Este resultado es consistente con instancias de sobre-reacción. ${ }^{4}$ A partir de estos resultados, se puede inferir que las expectativas se actualizan de manera parcial

\footnotetext{
${ }^{4}$ Diversos argumentos pueden explicar los eventos de sub-reacción y sobre-reacción. En particular, la heurística de representatividad (Barberis y coautores 1998), inatención (Sims 2003), manadas (Bischi y coautores. 2006).
} 
e incompleta. ${ }^{5}$ Esta evidencia sugiere la conveniencia de ir más allá de los postulados de los modelos FIRE (full-information rational expectations). ${ }^{6}$

Con el objetivo de apreciar si existen diferencias en el proceso de formación opiniones sobre el desempeño económico por parte de los individuos, se utilizó información disponible en la encuesta referida a variables sociodemográficas. Particularmente, información relativa al nivel educativo y la edad de los individuos. A partir de este análisis, no se encuentra evidencia estadísticamente significativa que permita inferir diferencias en las respuestas a los distintos flujos de información en función a su nivel educativo y edad. ${ }^{7}$ Dichos resultados contrastan con la evidencia reportada por Das, Kuhnen y Nagel (2017), quienes reportan diferencias en las creencias entre individuos según su estatus socioeconómico. Específicamente, encuentran que aquellos individuos con mayor ingreso o mayor nivel educativo son relativamente más optimistas respecto a las condiciones económicas futuras. También contrastan con el trabajo de Brown y Taylor (2006), quienes encuentra que los individuos jóvenes son más optimistas respecto de aquellos individuos adultos y, además, encuentran que el optimismo financiero está positivamente asociado con el nivel educativo de los individuos.

Teniendo en cuenta la baja capacidad que tienen los modelos propuestos para explicar la variabilidad de las opiniones de los individuos, tiene sentido intentar corregir la medida de opiniones. Una conjetura es que dicha variabilidad se deba en parte a cuestiones no asociadas al arribo de noticias económicas, por ejemplo, eventos políticos. Por lo tanto, una alternativa, en pos de corregir la medida de opiniones, está asociada a prescindir de las personas que informan una fuerte inclinación política en este conjunto de encuestas. Esta modificación buscar eliminar la variabilidad explicada por cuestiones políticas. Bajo esta conjetura, se espera un aumento en la capacidad explicativa del modelo. Por ejemplo, Huberman y coautores (2018) combinando datos de encuestas y búsquedas, evidencian que las expectativas de los encuestados que se asocian con el partido político entrante al poder mejoran sustancialmente sus expectativas económicas, mientras que los encuestados que se asocian al partido que deja el poder se vuelven más pesimistas. Los resultados hallados a partir de este ejercicio adicional confirman aquellos descriptos anteriormente, a saber, la existencia de ineficiencia en el proceso de formación de expectativas, la presencia de individuos con recurso cognitivo limitados e instancias de sub y sobre-reacción a flujos entrantes de información por parte de los encuestados. Es decir, se encuentra que los resultados son robustos. Sin embargo, la variabilidad de las opiniones explicada por este modelo aun es baja denotando las dificultades asociadas a aumentar la proporción de la variabilidad explicada por el arribo de noticias económicas.

Este trabajo pertenece a un grupo de contribuciones que analizan expectativas y percepciones de los agentes económicos. Estas contribuciones analizan la presencia de rigideces en la información, ${ }^{8}$ inatención, ${ }^{9}$ procesos de aprendizaje social ${ }^{10}$ y memorias

\footnotetext{
${ }^{5}$ Este resultado es consistente con modelos en los cuales la actualización de las expectativas ocurre de manera escalonada (Mankiw y Reis 2002, Mankiw, Reis y Wolfers 2004).

${ }^{6}$ Coibion y Gorodnickenko (2012).

${ }^{7}$ Ver, por ejemplo, Souleles (2004), Das, Kuhnen y Nagel (2017) y Malmendier y Nagel (2013).

${ }^{8}$ Coibion y Gorodnickenko (2012), Lamla (2008), Mankiw y Reis (2002), Woodford (2001), Sims (2003,2010).

${ }^{9}$ Woodford (2001), Sims (2003, 2010)

${ }^{10}$ Carroll (2003a, 2003b), Blinder y Krueger (2004), Dominitz y Manski (2005), Lamla (2008) y Malmendier y
} 
imprecisas. ${ }^{11}$ Dicha evidencia es inconsistente con expectativas racionales bajo información completa (full-information rational expectations - FIRE) ${ }^{12}$ donde los agentes utilizan toda la información disponible para realizar pronósticos eficientes, en base al conocimiento del modelo económico. En otras palabras, este trabajo es inconsistente con la noción de expectativas racionales, la cual identifica la coincidencia entre las previsiones o pronósticos que un modelo atribuye a los agentes y aquellas que deberían ser generadas por el propio modelo (Heymann y Pascuini, 2017).

Adicionalmente, este trabajo está relacionado con un conjunto de estudios que aproximan las expectativas de los individuos a través de encuestas de opinión pública. ${ }^{13}$ Estos estudios se concentran en medidas de expectativas de los individuos y sus vínculos con la evolución de indicadores sobre las condiciones económicas (Mankiw et al. 2004, Brown y Taylor 2006, Malmendier y Nagel 2013, Das, Kuhnen y Nagel 2017). Los patrones documentados en este estudio también son consistentes con la existencia de ineficiencias en el proceso de formación de expectativas, en coincidencia con los hallazgos expuesto por Souleles (2004) y Das, Kuhnen y Nagel (2017). Por último, este trabajo se relaciona con estudios que analizan la presencia de individuos con recursos cognitivos limitados. ${ }^{14}$

Luego de esta introducción, la siguiente sección resume la literatura relacionada. En la sección 3 , se describen los datos. La sección 4 describe la metodología. La sección 5 describe las estadísticas descriptivas. Los resultados preliminares se informan en la sección 6 . A continuación, en la sección 7 se discuten los resultados principales. En la sección 8 , se realiza un análisis teniendo en cuenta variables sociodemográficas, mientras que en la sección 9 se incorpora información referida a la inclinación política de los individuos. Por último, la sección 10 resume las conclusiones.

\section{Literatura relacionada}

Este trabajo está en línea con un conjunto de estudios que aproximan las expectativas de los individuos a través de encuestas de opinión pública. Si bien en muchos de ellos se explotan las percepciones reportadas por lo individuos para pronosticar el comportamientos de variables económicas, ${ }^{15}$ este trabajo se concentra en estudiar si los flujos de información pueden explicar la evolución de las opiniones. Brown y Taylor (2006) utilizan la encuesta de hogares de Reino Unido para explorar los determinantes de las expectativas financieras de los individuos. Estos autores encuentran que las predicciones de los individuos están influenciadas tanto por el ciclo de vida -individuos más

\footnotetext{
Nagel (2013).

${ }^{11}$ Mullainathan (2000), Sims (2003, 2010), Andrade y Le Bihan (2013) y Cavallo, Cruces y Perez-Tuglia (2016, 2017).

${ }^{12}$ Coibion y Gorodnickenko (2012).

${ }^{13}$ Ver, por ejemplo, Souleles (2004), Brown y Taylor (2006), Leduc y Sill (2010), Lanzilotta (2015) y Gennaioli, Ma y Shleifer (2015).

${ }^{14}$ Ver, por ejemplo, Woodford (2001), Sims (2003, 2010), Gorodnichenko (2008) y Coibion y Gorodnickenko (2012).

${ }^{15}$ Ver, por ejemplo, Souleles (2004), Brown y Taylor (2006), Leduc y Sill (2010), Lanzilotta (2015) y Gennaioli, Ma y Shleifer (2015).
} 
jóvenes son financieramente más optimistas respecto a aquellos individuos de mayor edad- como por el ciclo económico (los individuos son financieramente más pesimistas durante recesiones y más optimistas conforme la economía sale de la recesión). Además, encuentran que el optimismo financiero pasado tiene un efecto positivo sobre las expectativas financieras corrientes. Malmendier y Nagel (2013), a través de Encuesta de Consumidores de Michigan, encuentran que los agentes, cuando forman expectativas macroeconómicas (particularmente expectativas sobre inflación), asignan una mayor ponderación a hechos macroeconómicos experimentados durante su vida respecto a la ponderación asignada a otras fuentes históricas de datos disponibles. A su vez, Das, Kuhnen y Nagel (2017), encuentran un vínculo entre las opiniones de los individuos y sus características sociodemográficas. En particular, mediante el uso de la encuesta a los consumidores de Michigan, muestran que el estatus socioeconómico tiene una fuerte influencia sobre las creencias individuales sobre las condiciones futuras de la economía. Específicamente, encuentran que individuos con mayor nivel socioeconómico -individuos con mayor ingreso y mayor nivel educativo- son relativamente más optimistas respecto a las condiciones económicas futuras. Los resultados en este trabajo también guardan relación con los hallazgos expuestos por Mankiw, Reis y Wolfers (2004), quienes a partir del uso de múltiples encuestas de opinión pública, encuentran evidencia estadísticamente significativa referida a que los agentes no incorporan completamente la información macroeconómica en sus expectativas de inflación. Además, encuentran que los agentes parecen no reaccionar de manera adecuada a la información cuando forman sus expectativas respecto a dicha variable, evidenciando instancias de sub y sobre-reacción, siendo esto último consistente con la evidencia reportada por este trabajo.

Otro de los temas que se analiza en este trabajo, se refiere a la medida en que las expectativas reportadas por lo individuos proveen información sobre sus evaluaciones futuras. En particular, se analiza si existe ineficiencia en el proceso de formación de expectativas. Los resultados que se reportan en este trabajo van en línea con los expuestos por Souleles (2004), quien utiliza la encuesta de hogares de Michigan para testear la racionalidad de las expectativas de los consumidores y su utilidad para pronosticar el nivel de gasto de los hogares. Encuentra que las expectativas son sesgadas e ineficientes y que los errores de pronósticos de los individuos sobre varias variables macroeconómicas están sistemáticamente correlacionados con sus características demográficas. Por su parte, Das, Kuhnen y Nagel (2017), también reportan la existencia de sesgos en los pronósticos de los consumidores. Dichos autores comparan las creencias (reportadas en la encuesta) sobre el rendimiento futuro de las acciones y sus expectativas macroeconómicas con las realizaciones históricas a largo plazo de los rendimientos del índice bursátil y los pronósticos de la encuesta a pronosticadores profesionales, respectivamente. En base a estas dos últimas fuentes de información utilizadas como proxies de pronóstico eficientes, encuentran que los pronósticos de los individuos con mayor nivel educativo son relativamente menos sesgados que los pronósticos de aquellos con bajo nivel socioeconómico.

La evidencia reportada en este trabajo es consistente con la presencia de individuos con recursos cognitivos limitados que fallan al incorporar toda la información. ${ }^{16}$ Este resultado, está en línea con lo expuesto por Gorodnichenko (2008) quien muestra, en

\footnotetext{
${ }^{16}$ Ver, por ejemplo, Woodford (2001), Sims (2003, 2010).
} 
un modelo teórico, que la adquisición de información aumenta endógenamente poco después de la ocurrencia de un shock agregado a medida que los agentes económicos enfrentan mayor incertidumbre sobre el estado actual de la economía y, consecuentemente, les resulta beneficioso dedicar más recursos para aprender sobre las condiciones macroeconómicas actuales. En el mismo sentido, Coibion y Gorodnickenko (2012), evidencian que la adquisición de información depende del grado de rigidez de la misma y el grado de inatención de los individuos. Esto es consistente con la reasignación de recursos a la recopilación y procesamiento de información a la luz de las condiciones económicas.

Por último, las expectativas o previsiones que los agentes forman sobre la evolución futura de las variables económicas constituyen un elemento esencial en la dinámica futura de la economía. Una forma particular de especificar el proceso de formación de expectativas es asumir que los agentes utilizan toda la información disponible para generar un pronóstico eficiente. Esto último, se enmarca en la idea de expectativas racionales bajo información completa (full-information rational expectations - FIRE). ${ }^{17} \mathrm{Sin}$ embargo, la presencia de rigideces informativas, ${ }^{18}$ inatención, ${ }^{19}$ procesos de aprendizaje social, ${ }^{20}$ memorias imprecisas, ${ }^{21}$ justifican la reconsideración de los modelos FIRE, cuyas formulaciones son inconsistentes con este trabajo.

\section{Datos}

Los datos utilizados sobre expectativas y evaluaciones referidas al desempeño económico, se obtienen a partir de encuestas a individuos. Si bien la encuesta cubre muchos tópicos, por ejemplo, las expectativas y/o percepciones de los individuos, como así también, características sociodemográficas de las familias, en esta investigación sólo se tendrá en cuenta aquellas preguntas que analizan la trayectoria pasada y futura de la economía, las cuales admiten respuestas cualitativas a dichas preguntas.

\footnotetext{
${ }^{17}$ Coibion y Gorodnickenko (2012).

${ }^{18}$ Coibion y Gorodnickenko (2012) y Lamla (2008). Modelos con rigideces en la información pueden conducir a prescripciones de política que difieren de aquellas que surgen de modelos con información completa. Dentro de aquellos modelos con rigideces en la información, se encuentran: $i$ ) el modelo de información "sticky" desarrollado por Mankiw y Reis (2002), en el cual los agentes actualizan su set de información infrecuentemente producto del costo de adquirir y procesar dicha información. El grado de rigidez en la información en estos modelos corresponde a la probabilidad de no adquirir nueva información en cada periodo y $i i$ ) el modelo con información ruidosa desarrollados por Woodford $(2001)$, Sims $(2003,2010)$ en los cuales, los agentes actualizan su set de información continuamente, sin embargo, dado que nunca pueden observar el verdadero estado de los fundamentales, los agentes forman y actualizan sus creencias sobre los fundamentales preexistentes a partir de las señales. Por lo tanto, los pronósticos que realizan los agentes son un promedio ponderado de sus creencias previas y la nueva información que reciben. Entonces, el grado de rigidez en la información en estos modelos, corresponde al ponderador asignado a las creencias previas.

${ }^{19}$ Woodford (2001), Sims (2003, 2010).

${ }^{20}$ Carroll (2003a, 2003b), Blinder y Krueger (2004), Dominitz y Manski (2005), Lamla (2008) y Malmendier y Nagel (2013).

${ }^{21}$ Mullainathan (2000), Sims (2003, 2010), Andrade y Le Bihan (2013) y Cavallo, Cruces y Perez-Tuglia (2016, 2017).
} 
Se analiza la formación de expectativas sobre la trayectoria de la performance económica y la evaluación actual de ésta para 18 países de América Latina y el Caribe para el periodo 1995-2016. Los países bajo estudio son: Argentina, Bolivia, Brasil, Chile, CoIombia, Costa Rica, Ecuador, El Salvador, Guatemala, Honduras, México, Nicaragua, Panamá, Paraguay, Perú, República Dominicana, Uruguay y Venezuela.

Las encuestas son realizadas anualmente, desde el año $1995,{ }^{22}$ por la Corporación Latinobarómetro. Esta ONG sin fines de lucro realiza un estudio de opinión pública en 18 países de América Latina a través de entrevistas. La muestra es diseñada de manera tal que sea representativa del $100 \%$ de la población de cada uno de los países, comprendiendo áreas urbanas y rurales. Por último, esta encuesta no sólo indaga acerca de las opiniones de los agentes referidas al desempeño económico, sino que también se centra en aspectos demográficos, educativos, de la salud de los encuestados, entre otros.

Tanto el indicador de evaluación contemporánea como el indicador de expectativa respecto al desempeño económico, son construidos usando las respuestas a las siguientes preguntas (las respuestas permitidas se encuentran dentro de los corchetes):

i) "¿Considera Ud. que la situación económica actual del país es mejor, igual o peor que hace doce meses?" [mejor, igual, peor]

ii) "¿Y en los próximos doce meses cree Ud que, en general, la situación económica del país será mejor, igual o peor que ahora?" [mejor, igual, peor $]^{23}$

Dichas preguntas hacen referencia a la situación económica de un país y, en particular, indagan sobre la creencia de un individuo respecto a la misma. Teniendo en que cuenta la influencia que ejercen las creencias económicas de los individuos sobre su comportamiento y, en última instancia, sobre la dinámica de los agregados macroeconómicos, ambas preguntas pueden ser utilizadas para analizar la evolución de la situación económica. En este sentido, la primera pregunta solicita la opinión del encuestado sobre el desempeño económico actual, mientras que la segunda indaga acerca de la perspectiva económica dentro de los próximos 12 meses. Dada la estructura de cada pregunta, adicionalmente, puede utilizarse aquella referida a las expectativas de los individuos como un pronóstico de las futuras evaluaciones de estos. ${ }^{24}$ Ambas preguntas, admiten una respuesta que está restringida a caer en una de tres categorías: mejor, igual, peor. Respuestas favorables a ambas preguntas responden a opiniones positivas de los agentes respecto al desempeño económico.

Los flujos de información son aproximados a través de tres variables. Por un lado, se construye un indicador que refleja información sobre cambios en la tasa de crecimiento de la economía. Este es construido utilizando los datos de PBI a precios constantes en dólares del Banco Mundial. ${ }^{25}$ Por otro lado, la variable que captura la vulnerabilidad o

\footnotetext{
${ }^{22}$ Con excepción de los años 1999, 2012 y 2014, en los cuales, no se realizó dicha encuesta.

${ }^{23}$ Ambas preguntas admitieron a partir del 2001 al 2015 las respuestas: mucho mejor, un poco mejor, igual, un poco peor, mucho peor. Por lo tanto, con el objetivo de obtener una medida que pueda ser comprable a lo largo de todo el período, dichas respuestas fueron tratadas utilizándose las categorías inicialmente propuestas por las encuestas (a saber: mejor, igual o peor), según corresponda el caso.

${ }^{24}$ En el Apéndice A se desarrolla, de manera más extensa, la relación entre ambas variables.

${ }^{25} \mathrm{https}: / /$ data.worldbank.org/indicator
} 
fortaleza en el frente externo de un país está dada por el saldo del balance de cuenta corriente como porcentaje del PBI. Estos datos también se obtuvieron de la página de datos del Banco Mundial. Por último, se construye un indicador de opiniones económicas inferidas a partir del contenido de la prensa internacional. La elección de dichas variables económicas responde a que se considera que las opiniones de los individuos sobre la performance económica, no dependen solo de anuncios públicos de estadísticas económicas, sino que también dependen de información y juicios prospectivos reflejados en la prensa. Estos tres flujos de información, serán desarrollados con más detalle en la siguiente sección.

Por último, se utilizan la tasa de desempleo y la tasa de inflación para realizar un análisis de robustez, teniendo en cuenta que ambas variables también caracterizan la dinámica macroeconómica de un país. Los datos referidos a estas dos últimas variables, se obtuvieron del Banco Mundial.

\section{Metodología}

\subsection{Cuantificación de las respuestas de los individuos}

Como se ha mencionado anteriormente, en este trabajo se utilizan medidas de expectativas y de evaluación de la performance económica, las cuales se construyen a partir de las respuestas de los individuos a preguntas formuladas en encuestas. Dichas preguntas fueron presentadas en la sección anterior.

Siguiendo a Lahiri y Zhao (2015), una primera tarea es cuantificar las respuestas cualitativas que se desprenden de las encuestas. Para ello se propone un modelo empírico en el que se postula que $y_{i t}^{*}$ es una variable continua que varía en el tiempo, la cual representa la expectativa y/o evaluación de un individuo específico sobre la trayectoria actual o futura de la economía. El subíndice $i$ indica el individuo y el subíndice $t$ se refiere al periodo en el cual se hace la encuesta. Se define a $h$ como el horizonte o periodo durante el cual es formada la expectativa y/o evaluación sobre la trayectoria futura o contemporánea de la economía, respectivamente. Se asume la existencia de una variable continúa latente $y_{t}^{*}$, la cual es la expectativa agregada e igual para todos los individuos, ${ }^{26}$ entonces la expectativa y/o evaluación de un individuo $i$, en un año dado $t$, viene dada por $y_{i t}^{*}=y_{t}^{*}+\varepsilon_{i t}$, donde $\varepsilon_{i t}$ es el elemento idiosincrático. La información cuantitativa de $y_{i t}^{*}$ corresponde al individuo $i$, a partir de la cual se deriva a partir de la respuesta cualitativa a la pregunta realizada en la encuesta.

Existe una serie de encuestas $T$ realizadas, en cada país, desde el periodo $1-h$ hasta el periodo $T-h$, donde cada encuesta $t$ tiene $N_{t}$ encuestados. Supongamos que la pregunta de la encuesta relevante para $y_{i t}^{*}$, admite $j=1,2, \ldots, J$ categorías de respuestas discretas y las respuestas individuales son $y_{i t} \in\{j=1,2, \ldots, J\}$. Se asume la existencia de umbrales latentes conocidos $\delta_{i t, j}, \in\{j=1,2, \ldots, J\}$, los cuales puede ser específicos para cada individuo. Los parámetros $\left(-\delta_{i t, j}, \delta_{i t, j}\right)$ son mayores que cero en valor absoluto y determinan el intervalo de indiferencia para el cual el encuestado

\footnotetext{
${ }^{26}$ Éste puede interpretarse como la creencia que tienen los individuos, en cualquier periodo del tiempo, sobre la trayectoria de la economía, la cual tiene un valor "fundamental" subyacente (Carroll, 2003b).
} 
no espera cambio en la variable. A su vez, el encuestado contestará que espera un aumento de la variable si $y_{i t}^{*} \geq \delta_{i t, j}$, y que espera una disminución si $y_{i t}^{*} \leq-\delta_{i t, j}$. Se supone que dichos umbrales son homogéneos entre individuos.

La cuantificación se realiza computando la proporción de respuestas para cada una de las categorías. Por lo tanto, vamos a usar el código 1 para la respuesta "mejor", el código 0 para "igual" y -1 para la respuesta "peor", siguiendo Souleles (2004).

Haciendo $\mu_{t}=N_{t}^{-1} \sum_{i=1}^{N_{t}} I\left\{y_{i t}=1\right\}$ y $d_{t}=N_{t}^{-1} \sum_{i=1}^{N_{t}} I\left\{y_{i t}=-1\right\}$ siendo estas la proporción de encuestados que han dado una respuesta codificada con "1" y "-1", respectivamente.

A partir de esto definimos:

$$
\begin{gathered}
{ }_{t} I_{t}=\mu_{t}-d_{t}=N_{t}^{-1} \sum_{i=1}^{N_{t}} I\left\{y_{i t}=1\right\}-N_{t}^{-1} \sum_{i=1}^{N_{t}} I\left\{y_{i t}=-1\right\} \\
{ }_{t} I_{t+k}=\mu_{t}-d_{t}=N_{t}^{-1} \sum_{i=1}^{N_{t}} I\left\{y_{i t}=1\right\}-N_{t}^{-1} \sum_{i=1}^{N_{t}} I\left\{y_{i t}=-1\right\}
\end{gathered}
$$

Donde ${ }_{t} I_{t}$ representa la evaluación del desempeño económico que realizan los individuos $y_{t} I_{t+k}$ representa la expectativa sobre el desempeño económico que formulan estos. Es decir, estas dos variables subjetivas se toman como una proxy que caracteriza el proceso de formación de opiniones de los individuos respecto al desempeño económico. Por lo tanto, el valor agregado de ${ }_{t} I_{t}$ y ${ }_{t} I_{t+k}$, en un momento dado, es el número de personas que ha respondido +1 al ser encuestado menos la cantidad de personas que respondieron -1. Este indicador omite las personas que respondieron 0 . Por lo tanto, valores más elevados de estos indicadores denotan buenos estados.

Teniendo en cuenta la manera en que se han definido las variables ${ }_{t} I_{t}$ y ${ }_{t} I_{t+k}$, se puede construir un indicador que resuma estas dos medidas. En particular, se define un indicador de creencias:

$$
{ }_{t} I_{t+k}
$$

el cual representa las opiniones emitidas en el momento $t$ sobre el desempeño económico en $t+k$. Esta medida, dada la estructura de las preguntas, es un indicador de desempeño económico relativo aquel exhibido doce meses en el pasado. A su vez, $k$ admite sólo dos valores: $k=\{0,1\}$. En primer lugar, si $k=0$ la creencia reportada se refiere al desempeño económico contemporáneo en relación a aquel exhibido 12 meses en el pasado. En segundo lugar, si $k=1$ reporta la creencia sobre el desempeño económico en los próximos 12 meses respecto a la performance actual (o bien, reporta una creencia sobre el desempeño económico en $t+1$ respecto a la performance 12 meses en el pasado). 


\subsection{Medidas de flujo de información}

Este trabajo evalúa si los flujos de información están sistemáticamente asociados a cómo los individuos forman sus opiniones respecto a la actividad económica. Tres alternativas son utilizadas para capturar dichos flujos, las cuales se describirán a lo largo de esta sección. La primera, un indicador de la performance de crecimiento pasada. La segunda, los saldos del balance de cuenta corriente como porcentaje del PBI. Por último, un índice del tono de las noticias en la prensa.

\subsubsection{Indicador de aceleración}

El arribo de nueva información sobre la tasa de crecimiento de la economía se espera que influya en la formulación de opiniones por parte de los individuos. En este sentido, un indicador del flujo de información analizado en este trabajo, por lo tanto, está relacionado a cambios en la tasa de crecimiento económica. Siguiendo Aromi (2016), se construye un indicador de aceleración el cual compara la tasa de crecimiento reciente con la tasa de crecimiento para un periodo precedente más extenso. Sea $g_{c\left[t^{\prime}, t^{\prime \prime}\right]}$ la tasa de crecimiento anual del PBI para el periodo que comienza en $t^{\prime}$ y finaliza en $t^{\prime \prime}$. Durante el análisis posterior, la atención va a estar puesta sobre el indicador de aceleración del crecimiento para el periodo $[t-k, t]$, para el caso de expectativas y para el caso de evaluación del desempeño económico. Éste indicador está dado por $I_{c[t-k, t]}^{G}=g_{c[t-k, t]}-g_{c[t-s, t-k]}$. Esto es, la diferencia entre la tasa de crecimiento anual, para el periodo más reciente de $(k)$ años y la tasa de crecimiento anual para el periodo de $(s-k)$ años anteriores.

En las evaluaciones desarrolladas más adelante se utilizarán dos especificaciones para capturar información histórica de corto plazo e información de mediano plazo. Por un lado, se considera un indicador de aceleración de crecimiento que compara información sobre crecimiento para el periodo $[t-1, t]$. Este indicador viene dado por: $I_{c[t-1, t]}^{G_{C}}=g_{c[t-1, t]}-g_{c[t-4, t-1]}$. Esto es, la diferencia entre la tasa de crecimiento anual para el periodo anterior de un año y la tasa de crecimiento anual para el periodo anterior de 3 años. Por último, el indicador de aceleración que captura información de mediano plazo para un país dado para el periodo $[t-3, t]$. Dicho indicador viene dado por: $I_{c[t-3, t]}^{G_{M}}=g_{c[t-3, t]}-g_{c[t-18, t-3]}$. En este caso, el indicador representa la diferencia entre la tasa de crecimiento anual entre el período más próximo de 3 años y la tasa de crecimiento anual para el periodo precedente de 15 años. ${ }^{27}$

La constitución de este tipo de indicadores permite evaluar si los individuos incorporan información referida a la performance de crecimiento de una economía en el proceso de formación de opiniones. Particularmente, se evaluará si la información referida a aceleraciones en la tasa de crecimiento explica las opiniones sobre desempeño económico. La utilización de dos indicadores permite inferir la medida en que las opiniones se basan en información más reciente o más distante.

\footnotetext{
${ }^{27}$ Una explicación más detallada sobre la elección de estos valores y la apertura del indicador de aceleración en un indicador de corto y mediano plazo, se exponen en el Apéndice B.
} 


\subsubsection{Indicador de vulnerabilidad externa}

El segundo indicador del flujo de información que se analiza en este trabajo corresponde al saldo del balance de cuenta corriente como porcentaje del PBI. Este indicador está dado por $I_{c[t]}^{C C}$, esto es, el saldo que toma dicho ratio en el periodo $t$.

Este indicador tiene por objeto captar si los agentes tienen en cuenta, a la hora de formar sus opiniones respecto al desempeño económico, cuáles son las condiciones externas del país. Se conjetura que el saldo del balance de cuenta corriente como porcentaje del PBI es un indicador apropiado de estas condiciones.

Si bien los saldos de cuenta corriente tomados en forma aislada no contienen información concluyente sobre el estado y las perspectivas de la economía, ${ }^{28}$ esta variable es incluida considerando que contiene información sobre vulnerabilidades o fortalezas que pueden influir en el desempeño futuro de la actividad económica. Un amplio conjunto de trabajos han estudiado la sostenibilidad del desbalance en la cuenta corriente, la reversión de la cuenta corriente y sus implicancias sobre la actividad económica. ${ }^{29}$ En estos trabajos se encuentra que la presencia de déficit en la cuenta corriente no necesariamente conduce a evaluaciones negativas. ${ }^{30}$

Teniendo en cuenta que los países de América Latina y el Caribe, a lo largo del periodo analizado, han presentado en promedio un déficit en la cuenta corriente del $3 \%$ de su PBI (ver tabla 1), este indicador parece constituirse como un síntomas de fragilidad externa. Por lo tanto, es menester en este trabajo intentar captar si los agentes ignoran (o no) este indicador de fragilidad externa al formular opiniones sobre el desempeño económico.

\subsection{3. Índice del tono de las noticias en la prensa}

Teniendo en cuenta que los periódicos comunican la nueva información económica que arriba a los organismos estadísticos, se espera que los individuos se informen sobre el contenido de dicha información a partir de las noticias en la prensa. A su vez, estas noticias periodísticas pueden reflejar información y opiniones que no difunden dichos organismos estadísticos. Por lo tanto, con el objetivo de resumir este tipo de flujo de información, se construyó un índice en base al contenido de la prensa mundial. Los niveles de optimismo y pesimismo van a ser aproximados capturando la frecuencia de palabras con contenido negativo en un subconjunto relevante de textos muestrales. En este apartado se propone un indicador que captura el tono en las noticias de la prensa, a partir del análisis lingüístico de textos y utilizando diccionarios especializados (Tetlock 2007).

Para capturar la información no estructurada distribuida por la prensa, se construyó una aproximación en base a los artículos periodísticos del diario Wall Street Journal,

\footnotetext{
${ }^{28}$ Heymann (1994)

${ }^{29}$ Ver, por ejemplo, Heymann (1994), Calvo (1998), Edwards (2004), Obstfed y Rogoff (2007) y Reinhart y Reinhart (2008).

${ }^{30}$ Ver, por ejemplo, Sachs (1981), Heymann (1994) y Blanchard y Giavazzi (2002).
} 
un periódico internacional con cobertura mundial..$^{31}$ Los mismos se adquirieron a través del proveedor de medios ProQuest ${ }^{32}$. Con el fin de obtener un set de artículos consistentes, nos concentramos en la sección de economía de este periódico. Por último, se explotan los artículos periódicos desde el 3 de enero de 1995 hasta el 31 de diciembre del 2016.

Este análisis parte del texto original, el cual inicialmente es descompuesto en palabras individuales (procedimiento denominado tokenización de texto) con la posterior eliminación de "stop words" -palabras comúnmente utilizadas por el idioma inglés que no poseen contenido relevante, tales como: "a", "but", "how", "to"- esto último se realiza con el objetivo de poder concentrarse en las palabras más relevantes para nuestros fines, dejando de lado las palabras que aparecen con mayor frecuencia. Además, siguiendo practicas habituales, se han eliminado del texto números y signos de puntuación y, por último, todo el texto se ha convertido a minúscula. Se construye un algoritmo, el cual computa un índice del tono como una aproximación al estado de las opiniones en la prensa. De esta forma se extrae el tono de las noticias en la prensa a partir del uso de técnicas de procesamiento de lenguaje natural.

Siguiendo Aromí (2016), el primer paso para construir este índice involucra fragmentos del texto asociados a cada país. Con este objetivo, se creó una lista de palabras para cada país. Las palabras claves utilizadas, incluyen: nombre del país, ciudad capital y gentilicio. Luego, para cada año del periodo muestral, se identifica el conjunto de artículos en los cuales está presente al menos una de estas palabras claves. Para cada uno de estos artículos, se selecciona la porción de texto que está lo suficientemente cerca a dichas palabras claves asociadas a los países. Específicamente, dicha selección corresponde a 50 palabras antes y 50 palabras después de la palabra clave identificada. El texto seleccionado para el país $c$ y el año $t$ es combinado formando una selección de texto $K_{c t}$. Esto concluye la etapa de extracción de texto.

Luego, para el cómputo de un indicador del tono de la información, se requiere identificar un set de palabras con contenido negativo. Siguiendo la contribución de Tetlock (2007), la lista de palabras negativas es construida usando la categoría "negativa" provista por General Inquirer, un sitio web que provee herramientas para el análisis de datos de texto. ${ }^{33}$ La lista original incluye 2291 palabras. Con el fin de mejorar la precisión del índice, se expandió esta lista original incluyéndose las formas de sustantivo plural, diferentes tiempos verbales y adverbios. Este procedimiento culmino con una nueva lista de 5364 palabras.

Sea $T_{c t}$ el número de palabras en $K_{c t}$, el texto seleccionado correspondiente al año $t$ y al país $c$ y, sea $N_{c t}$ el número de veces que la palabra negativa es identificada en $K_{c t}$. Entonces, el índice del tono en las noticias está dado por $S_{c t}=N_{c t} / T_{c t}$. Por lo tanto, un mayor valor de este índice es asociado a opiniones más pesimistas mientras que valores más bajos del mismo, son asociados a opiniones más optimistas.Por último, en pos de facilitar la interpretación de este indicador, el mismo es multiplicado por -1 con el objetivo de obtener $S_{c t}=-N_{c t} / T_{c t}$, esto sugiere que mayores valores en el índice

\footnotetext{
${ }^{31}$ Este enfoque ha sido utilizado con éxito en diversos trabajos: Tetlock (2007), Garcia (2013) y Aromí (2015).

${ }^{32}$ El texto se extrajo de: http://pqasb.pqarchiver.com/djreprint/.

${ }^{33} \mathrm{http}: / /$ www.wjh.harvard.edu/ inquirer/homecat.htm
} 
indican mayores niveles de optimismo en las opiniones de la prensa.

\section{Estadísticas descriptivas}

A partir de los datos que se exhiben en la tabla 1 , se desprende que para todo el periodo de la muestra analizado (1995-2016), el número promedio de palabras negativas en un artículo representa el $6 \%$ del total de palabras, es decir, un artículo típico posee un cierto nivel de pesimismo en el tono de las noticias en la prensa.

Por otro lado, se puede observar que la media de las expectativas de los individuos $\left({ }_{t} I_{t+1}\right)$ respecto a la futura performance de la economía está centrada en 0.04 . Esto indica que, en promedio, la proporción de personas que cree que la economía mejorará fue levemente mayor a la proporción de personas que cree que la economía emporará. Sin embargo, la mediana de esta variable se encuentra a la izquierda de su medía, indicando la presencia de cierto nivel de asimetría en la distribución. De aquí se desprende que poco más de la mitad de los individuos posee expectativas menos optimistas respecto al futuro de la performance económica. A su vez, este indicador alcanzó su máximo en Brasil en el año 2010, que en dicho año alcanzó una tasa de crecimiento interanual del $7,5 \%$ (su mayor alza desde 1986), luego de haber registrado una contracción moderada en el año 2009. ${ }^{34}$

Al observar el indicador de evaluación de la situación actual de la economía por parte de los individuos ${ }_{t} I_{t}$, se encuentra que la media es similar a la mediana. Ambas medidas son negativas, esto indica que, en promedio, es mayor la proporción de personas que cree que la situación económica durante los últimos doce meses, en general, estuvo mejor respecto a la performance actual. Este indicador alcanzó su máximo en Paraguay en el año 2008, año en el cual el PBI creció a una tasa interanual del 6,36\% y cuya economía se beneficiaba del boom en la demanda internacional de commodities (soja y carne en el caso paraguayo). ${ }^{35}$ Por último, tanto las evaluaciones como el indicador de expectativas registran su mínimo en Honduras en el año 1996 (ver tabla 1).

Continuando con el análisis de estadística descriptiva de los flujos de información, como se desprende de la tabla 1 los países de la región durante el periodo 1995-2016, presentaron, en promedio, un déficit en cuenta corriente de $3 \%$ de su PBI. El valor mínimo del saldo cuenta corriente como porcentaje del PBI lo registró Nicaragua en el año 1997, mientras que el valor máximo de este indicador lo alcanzó Venezuela en el año 2005 (este boom respondió a la tendencia alcista, marcada desde 1999, del precio del petróleo por barril). Durante el mismo periodo, tanto la tasa de desempleo como la tasa de inflación, en promedio, se ubicaron en el orden del $8 \%$. Sin embargo, la tasa de desempleo presentó un máximo de $19 \%$, el cual fue registrado en Colombia en el año 2000, mientras que el valor más alto de la tasa de inflación lo alanzó Venezuela en el año 2015. Por último, observando la tasa de crecimiento interanual podemos concluir que si bien los países, en promedio, crecieron al $4 \%$ durante el periodo bajo análisis, este nivel presentó una fuerte volatilidad (desvío igual al $3 \%$ ). El valor mínimo que de

\footnotetext{
${ }^{34}$ Según el World Economic Outlook del FMI, disponible en: https://www.imf.org/external/pubs/ft/weo/data/WEOhistorical.xlsx

${ }^{35}$ Según el World Economic Outlook del FMI, disponible en: https://www.imf.org/external/pubs/ft/weo/data/WEOhistorical.xIsx
} 
este indicador económico lo registró Argentina en el año 2002 (durante una severa crisis económica desde 1998), mientras que el valor máximo lo alcanzó Venezuela en el año 2004.

\section{Tabla 1: Estadísticas descriptivas}

La tabla 1 presenta las estadísticas descriptivas del total de palabras $(t)$, las palabras negativas $(n)$, el indicador del tono en las noticias de la prensa bruto $(s)$, el indicador de expectativas de los individuos $\left({ }_{t} I_{t+1}\right)$, indicador de evaluación $\left({ }_{t} I_{t}\right)$, la tasa de crecimiento interanual $(g)$, el saldo de cuenta corriente como porcentaje del PBI $(c c)$, la tasa de desempleo $(\mu)$ y la tasa de inflación $(\pi)$

\begin{tabular}{lrrrrrrr}
\hline & Media & Mediana & Desvío Estandar & Q1 & Q3 & Mínimo & Máximo \\
\hline$t$ & 7082.40 & 1723.50 & 13889.17 & 604.75 & 6496.00 & 4.00 & 92529.00 \\
$n$ & 406.27 & 91.00 & 797.98 & 33.75 & 364.50 & 0.00 & 5759.00 \\
$s$ & -0.06 & -0.06 & 0.02 & -0.07 & -0.05 & -0.18 & 0.00 \\
${ }_{t} I_{t+1}$ & 0.04 & 0.01 & 0.24 & -0.14 & 0.19 & -0.74 & 0.75 \\
${ }_{t} I_{t}$ & -0.17 & -0.19 & 0.27 & -0.37 & -0.00 & -0.81 & 0.50 \\
$g$ & 0.04 & 0.04 & 0.03 & 0.02 & 0.06 & -0.11 & 0.18 \\
$c c$ & -0.03 & -0.03 & 0.05 & -0.05 & -0.01 & -0.19 & 0.17 \\
$\mu$ & 0.08 & 0.07 & 0.04 & 0.05 & 0.10 & 0.01 & 0.19 \\
$\pi$ & 0.08 & 0.06 & 0.10 & 0.04 & 0.09 & -0.01 & 0.74 \\
\hline
\end{tabular}

\section{Evaluación preeliminar}

En esta sección, se evalúa la asociación entre el proceso de formación de opiniones referidas al desempeño económico y los flujos de información a través de un modelo simple. Más específicamente el indicador de desempeño económico relativo ${ }_{t} I_{t+k}, k=\{0,1\}$, es estimado como una función de los flujos de información $I^{j}$, donde $j \in\left\{G_{C}, G_{M}, C C, S\right\}$, donde $G_{C}$ es el indicador de aceleración constituido con una ventana corta de tiempo, $G_{M}$ es el indicador de aceleración de crecimiento para una ventana más extensa, $C C$ corresponde al indicador de vulnerabilidad externa y $S$ refiere al indicador del tono de las noticias en la prensa. A su vez, se incorporan posteriormente los flujos de información asociados a la tasa de inflación y a la tasa de desempleo.

\subsection{Evaluación del desempeño económico y flujos de información}

En este apartado se analizará la asociación entre la evaluación de la performance contemporánea de la economía realizada por los individuos y los distintos flujos de información. Se supone que los agentes forman su evaluación sobre la situación económica actual condicional a la información económica de interés al momento de realizarse dicha encuesta. Dado que los individuos son consultados en $t$ respecto a la performance actual relativa al estado de la economía doce meses en el pasado, la respuesta de 
éstos tendrá en cuenta la información disponible al momento de ser encuestados.

La relevancia de este modelo radica en la posibilidad de anticipar cuál será el impacto de ciertos cambios en las políticas económicas y evaluar cómo los agentes están incorporando la información disponible sobre el desempeño económico actual. Teniendo en cuenta la trascendencia que adquieren los reportes subjetivos sobre el comportamiento de los individuos, adquiere una sustancial importancia comprender cómo los individuos evalúan la performance económica actual, aún más si se tiene en cuenta el papel que puede tener esta evaluación sobre sus expectativas. Desde el punto de vista del diseño de política económica, contar con este tipo de insumo permite evaluar si los cambios en dichas políticas están obteniendo los resultados en la forma prevista. Además, permite analizar si dichos reportes subjetivos se fundamentan en indicadores objetivos de las condiciones económicas. En este ejercicio, se describe la forma en que las opiniones acerca de la evaluación del desempeño económico actual están asociadas a los flujos de información.

En este sentido, las creencias reportadas por los individuos, al momento de ser encuestados, sobre el desempeño económico contemporáneo relativo a aquella performance exhibida hace un año ${ }_{t} I_{t}$, se estiman como una función de los flujos contemporáneos de información, es decir, condicional a la información disponible en $t$. El modelo de datos en panel es:

$$
{ }_{t} I_{t, c}=\alpha_{t}+\alpha_{c}+\beta_{G_{C}} I_{[t-1, t] c}^{G_{C}}+\beta_{G_{M}} I_{[t-3, t] c}^{G_{M}}+\beta_{C C} I_{[t] c}^{C C}+\beta_{S} I_{[t] c}^{S}+\mu_{[t] c}
$$

donde $c$ indica el país, $\alpha_{t}$ representa el efecto fijo por período, el cual captura shocks globales que son comunes a todos los países en cada año. El coeficiente $\alpha_{c}$, es el efecto fijo por país, el cual captura características culturales e institucionales que difieren entre países, las cuales no varían en el tiempo. $\mu_{c[t]}$ es el término de error. $\beta_{G_{C}}, \beta_{G_{M}}$, $\beta_{C C}$ y $\beta_{S S}$, son los parámetros de interés a estimar correspondientes a cada uno de los flujos de información descriptos en la sección 3 , esto es, los indicadores de aceleración de crecimiento constituidos para una ventana corta y una ventana más extensa, el indicador de vulnerabilidad externa y el indicador del tono en las noticias, respectivamente. Por último, para facilitar las comparaciones de los coeficientes estimados, todas las variables explicativas han sido estandarizadas.

Bajo esta especificación, los agentes evalúan el desempeño contemporáneo de la economía teniendo en cuenta un indicador de crecimiento que se constituye con información más reciente sobre la performance de crecimiento pasada y el mismo indicador, pero constituido con información para una ventana más extensa. Por otro lado, las evaluaciones pueden estar asociadas al saldo del balance de cuenta corriente como porcentaje del PBI y al estado de las opiniones en la prensa. Dada la estructura de cada variable, se espera que el arribo de información positiva referida a cada una de estas, contribuya de manera favorable en la evaluación de la performance corriente respecto de aquella 12 meses en el pasado.

La tabla 2 muestra los resultados obtenidos que surgen de la estimación del modelo que intenta caracterizar la relación entre las evaluaciones formulada por los agentes y 
los flujos de información. Se puede observar que sólo los coeficientes de ambos indicadores de aceleración del crecimiento, cuando se los evalúa individualmente, resultan estadísticamente significativos. Es decir, la estimación indica que dichos flujos de información explican los cambios en las evaluaciones que formulan los agentes respecto al desempeño económico pasado (ver columna 1 y 2). Sin embargo, al observar la columna 3 y 4 , se desprende que el indicador de vulnerabilidad externa y el indicador de opiniones, parecen no ser relevantes individualmente para explicar las evaluaciones formuladas por los individuos.

Continuando con el análisis de la tabla 2, los resultados expuestos en la columna 5 permiten inferir que los flujos de información, excepto el indicador de opiniones en la prensa, son estadísticamente significativos y poseen el signo esperado. Particularmente, el indicador de cuenta corriente no sólo gana significatividad estadística, sino que también relevancia económica para explicar cómo los agentes formulan las evaluaciones de la performance económica. Sin embargo, el indicador de opiniones en la prensa continúa sin ser estadísticamente significativo bajo esta especificación.

Si observamos con más detalle los resultados de la columna 5 , se desprende que un aumento de una desviación estándar en la medida de aceleración económica en el corto plazo está asociado a un aumento de $5,4 \%$ en la esperanza del indicador de evaluaciones económicas. Este coeficiente, aumenta significativamente si se observa un incremento de una desviación estándar en la medida de aceleración económica en el mediano plazo, en este caso, dicha variación está asociada a un aumento, en promedio, de $11,8 \%$ en la proporción de individuos que esperan una mejora de la performance económica corriente respecto a la pasada. En otras palabras, un incremento de un desvío estándar de este indicador de aceleración, en promedio, aumenta 0.44 desvíos estándares la medida de evaluación de la performance económica actual. Teniendo en cuenta que el indicador de aceleración más informativo es aquel conformado con información más extensa, esto podría responder a porque los individuos asignan una mayor importancia a dicho indicador.

Por otro lado, la columna 5 sugiere, además, que un incremento en un desvío estándar en el saldo del balance de cuenta corriente, en promedio, está asociado a un aumento de $3,8 \%$ en la proporción de individuos que consideran que la performance económica actual se encuentra en una situación mejor respecto a la situación económica pasada, siendo este indicador estadísticamente significativo al $5 \%$. Por lo tanto, este resultado sugiere que los agentes tienen en cuenta la dinámica del balance de cuenta corriente para evaluar la situación económica actual. Además, el coeficiente de este indicador adquiere significatividad económica y estadística en relación al modelo especificado en la columna 3 . Esto último permite inferir que al controlar por el indicador aceleración, se ha corregido el sesgo del coeficiente del indicador de cuenta corriente asociado a la correlación negativa que existe entre el saldo de cuenta corriente y la aceleración del crecimiento. ${ }^{36}$ Otra observación se asocia a que este indicador, sólo parece ser relevante para explicar cómo evolucionan las opiniones cuando se lo evalúa en forma conjunta con otros indicadores, mientras que parece no serlo cuando se lo evalúa individualmente, como se mencionó anteriormente. Esto último es consistente

\footnotetext{
${ }^{36}$ La correlación entre el indicador de vulnerabilidad externa y el indicador de aceleración del crecimiento de mediano plazo es de -0.199 .
} 
con trabajos que interpretan que el saldo de la cuenta corriente aisladamente no contiene información concluyente. ${ }^{37}$ Por último, el indicador de opiniones en la prensa no es estadísticamente significativo bajo esta especificación. Por lo tanto, se puede inferir que los individuos no tienen en cuenta las opiniones predominantes en la prensa internacional cuando realizan una evaluación de la performance económica actual respecto de aquella 12 meses en el pasado. ${ }^{38}$

Con el objetivo de tener una medida más completa de cómo influyen las condiciones económicas sobre la formación de opiniones sobre la performance económica corriente, se incorporaron dos variables adicionales relevantes para explicar la dinámica económica. Dichas variables son la tasa de desempleo $(\mu)$ y la tasa de inflación $(\pi)$. Se espera que incrementos en estos indicadores impacten de manera negativa sobre la formulación de las evaluaciones de los individuos. Los resultados de esta nueva especificación se pueden observar en la columna 6. Observando dichos resultados se puede inferir que, por un lado, ambas variables poseen el signo esperado, por otro lado, ambas variables son estadísticamente significativas al $1 \%$. Se observa que los indicadores no solo contribuyen a explicar la evolución de las evaluaciones de la performance actual respecto de aquella exhibida 12 meses en el pasado, sino que, además, su relevancia economía no es despreciable. Por último, los coeficientes de los restantes flujos de información no presentan alteraciones considerables, manteniéndose los resultados anteriormente mencionados. ${ }^{39} 40$

Teniendo en cuenta los resultados mencionados en los párrafos anteriores, se pueden inferir asociaciones estadística y económicamente significativas entre la medida de opinión sobre desempeño económico contemporáneo y el arribo de información correspondiente a cierto conjunto de indicadores económicos. Esto último, se puede concluir a partir del test-F de significatividad conjunta de los indicadores de flujos de información. En todos los casos, se puede inferir que dichos indicadores en conjunto son estadísticamente significativos, sugiriendo que estos pueden explicar cómo los individuos forman evaluaciones (exceptuando aquella especificación en la cual se evalúa individualmente el indicador de vulnerabilidad externa y el indicador de opiniones en la prensa internacional). Por otro lado, se pueden evaluar medidas alternativas de la capacidad explicativa de dichos indicadores de las opiniones de los individuos respecto

\footnotetext{
${ }^{37}$ Heymann (1994).

${ }^{38}$ Los resultados reportados en la columna 5 de la tabla 2, no varían sustancialmente cuando se regresa un modelo con igual especificación pero controlando por el rezago del indicador de evaluaciones, con excepción del indicador de vulnerabilidad, el cual deja de ser estadisticamente significativo.

${ }^{39} \mathrm{Sin}$ embargo, tanto la tasa de inflación como la tasa de desempleo, dejan de ser estadisticamente significativos cuando se regresa un modelo con igual especificación pero controlando por el rezago del indicador de evaluaciones. A excepción de estos dos indicadores, los resultados remanentes exhibidos en la columna 6 , se mantienen.

${ }^{40}$ Los resultados exhibidos en la columna 5 y 6 de la tabla 2, se mantienen cuando excluimos del análisis los outliers o valores atípicos del indicador de evaluación sobre el desempeño económico contemporáneo. Respecto al tratamiento de estos últimos, se realizaron tres ejercicios: $i$ ) se estimó el mismo modelo pero excluyendo el valor mínimo y el valor máximo de la medida de evaluación; ii) se estimó el modelo excluyendo aquellas observaciones que se encuentran arriba del percentil 99 y por debajo del primer percentil del indicador de evaluación; iii) se estimó el modelo excluyendo aquellas observaciones que se encuentran por debajo del percentil 5 y por encima del percentil 95 del indicador de evaluación. En particular, la significatividad estadística de los coeficientes se mantienen, mientras que la magnitud de los coeficientes se contrae en los tres ejercicios, con excepción del indicador de cuenta corriente, cuyo coeficiente que adquiere una mayor magnitud.
} 
al desempeño económico. Una medida que nos permite abordar esto último se infiere a partir del coeficiente de determinación $\left(R^{2}\right)$. En este sentido, es posible analizar el $R^{2}$ - within que se deriva de una estructura de datos en panel. ${ }^{41}$ Este estadístico permite apreciar la bondad del ajuste contemplando la presencia de heterogeneidad no observada por individuo y por periodo. Sin embargo, dicha medida subestima la capacidad explicativa de los indicadores económicos, ya que en un modelo within las variables han sido transformadas en pos de contemplar la presencia de dicha heterogeneidad. Por lo tanto, tiene sentido analizar el coeficiente de determinación $R^{2}-$ agrupado. el cual se deriva de regresar el mismo modelo sin contemplar la estructura de panel, es decir, ignorando la heterogeneidad no observable. ${ }^{42} \mathrm{~A}$ partir de esta medida, se puede inferir la capacidad explicativa del conjunto de los indicadores sin contemplar dichos efectos fijos.

En base a esto último, en la tabla 2 se reporta el $R^{2}$ - ajustado correspondiente a ambos modelos. Como puede apreciarse, en el modelo within, los flujos de información explican una fracción no despreciable de la variabilidad de las evaluaciones. Por ejemplo, el $R^{2}$ - ajustado que se observa en la columna 6 es igual a $22,8 \%$. Sin embargo, el modelo puede explicar una mayor fracción de la variabilidad del indicador de evaluaciones cuando no se tiene en cuenta la heterogeneidad por país y por periodo. Esto se puede inferir al observar el $R^{2}$ - ajustado del modelo agrupado, el cual asciende a $25,3 \%$ bajo la especificación del modelo expuesto en la columna 6 .

En este apartado se reportan dos resultados complementarios, por un lado, se establecen asociaciones estadística y económicamente significativas entre los flujos de información y la medida de opinión referida al desempeño económico contemporáneo. Los signos de dichas asociaciones son consistentes con los esperados. Por otro lado, cuando se analiza cuál es la capacidad que poseen estos flujos para explicar la variabilidad de las opiniones de los individuos, las medidas sugieren que las variables utilizadas en este trabajo no logran explicar una fracción importante de la variabilidad de las opiniones. Una posible interpretación de este último resultado, puede ser cierta imprecisión en las mediciones de los indicadores económicos subjetivos utilizados en este trabajo, variables económicas relevantes que han sido omitidas y/o factores relacionados al procesamiento de la información que intervienen en el proceso de for-

${ }^{41}$ El $R^{2}$ y $R^{2}-$ ajustado de un modelo within se obtiene de:

$$
R^{2}-\text { within }=1-\frac{S C R}{S C T}
$$

Donde SCR es la suma de cuadrados residuales y SCT es la suma de cuadrados totales. Dichas medidas se obtienen a partir de la regresión:

$$
y_{i t}-\bar{y}_{i}-\bar{y}_{t}+\bar{y}=\left(x_{i t}-\bar{x}_{i}-\bar{x}_{t}+\bar{x}\right) \beta+\left(\nu_{i t}-\bar{\nu}_{i}-\bar{\nu}_{t}+\bar{\nu}\right)
$$

Una explicación detallada se puede encontrar en Baltagi (2013).

${ }^{42}$ El $R^{2}$ y $R^{2}-$ ajustado de un modelo agrupado se obtiene de regresar $y_{i t}=x_{i t} \beta+\nu_{i t}$ utilizando el método de MCO. 
mación de opiniones que no han sido contemplados, es decir, no han sido incorporados en el modelo. ${ }^{43}$

\subsection{Expectativas sobre desempeño económico y flujos de información}

En este apartado analizaremos la asociación entre la expectativa sobre la performance económica que forman los individuos y los distintos flujos de información. Se propone un modelo empírico en el que los agentes forman expectativas condicionales a la información económica disponible al momento en que se realiza dicha encuesta. Dado que los individuos son consultados en $t$ respecto a la performance de la economía en $t+1$, la respuesta de éstos tendrá en cuenta la información en $t$.

Teniendo en cuenta el impacto de las expectativas de los individuos sobre diversas variables de la economía, es de interés comprender cómo se definen estas expectativas. Una conjetura es que contribuiría a predecir cómo reaccionan los agentes a ciertos cambios en la política económica. Por lo tanto, esta información adquiere una relevancia sustancial desde el punto de vista de los hacedores de política y el diseño de política económica. En este sentido, este ejercicio descriptivo busca ilustrar la medida en que las expectativas de los agentes económicos responden a distintas formas de información.

Las creencias reportadas por los individuos, sobre el desempeño económico en los próximos doce meses respecto a la performance económica corriente $\left({ }_{t} I_{t+1}\right)$, se estiman como una función de los flujos contemporáneos de información. El modelo de datos en panel es similar al expuesto en la subsección 6.1, es decir, se utilizan el mismo conjunto de variables explicativas.

Bajo esta especificación, los agentes forman sus expectativas sobre la dinámica futura de la economía teniendo en cuenta un indicador de crecimiento que se construye con información más reciente sobre la performance de crecimiento pasada y el mismo tipo de indicador, pero constituido con información para una ventana más extensa. Por otro lado, dada la especificación anteriormente mencionada, las expectativas pueden estar asociadas o no al saldo del balance de cuenta corriente como porcentaje del PBI y al estado de las opiniones en la prensa. Teniendo en cuenta la estructura de cada variable, se espera que el arribo de información positiva referida a cada una de estas variables contribuya de manera positiva en la formación de expectativas, por parte de los individuos, respecto a la performance económica futura.

La tabla 3 muestra los resultados de la estimación del modelo que caracteriza la relación entre las expectativas formuladas por los agentes y los flujos de información. Se puede observar que los coeficientes, excepto aquel asociado al indicador de vulnerabilidad externa y la medida que captura las opiniones en la prensa internacional, resultan significativos si se los evalúa aisladamente (ver columnas 1 a 4). Es decir, la estimación indica que las variables de flujo de información explican los cambios en las expectativas que formulan los agentes respecto al desempeño económico.

\footnotetext{
${ }^{43}$ Por ejemplo, factores relacionados a la dinámica de las opiniones en contextos de aprendizaje social (Golub y Jackson, 2010).
} 
Tabla 2: Evaluación del desempeño económico y flujos de información La tabla 2 reporta los coeficientes estimados del modelo:

$$
{ }_{t} I_{t, c}=\alpha_{t}+\alpha_{c}+\beta_{G_{C}} I_{[t-1, t] c}^{G_{C}}+\beta_{G_{M}} I_{[t-3, t] c}^{G_{M}}+\beta_{C C} I_{[t] c}^{C C}+\beta_{S} I_{[t] c}^{S}+\mu_{[t] c}
$$

La variable dependiente son las evaluaciones de los individuos $\left.{ }_{t} I_{t}\right)$. Los flujos de información son capturados a traves del indicador de aceleración del crecimiento constituido para una ventana corta de tiempo $\left(\beta_{G_{C}}\right)$, el indicador de aceleración de mediano plazo $\left(\beta_{G_{M}}\right)$, el indicador de vulnerabilidad externa $\left(\beta_{C C}\right)$ y el indicador del tono en las noticias de la prensa $\left(\beta_{S}\right)$. Por ultimo, son incorparadas al análisis, la tasa de inflación $(\pi)$ y la tasa de desempleo $(\mu)$ como variables alternativas que captan las condiciones macroeconómicas. Para facilitar la comparación entre los coeficientes estimados, todas las variables explicativas han sido estandarizadas.

\begin{tabular}{|c|c|c|c|c|c|c|}
\hline & (1) & $(2)$ & (3) & $(4)$ & $(5)$ & (6) \\
\hline$\beta_{G_{C}}$ & $\begin{array}{c}0.065^{* * *} \\
(0.012)\end{array}$ & & & & $\begin{array}{c}0.054^{* * *} \\
(0.015)\end{array}$ & $\begin{array}{c}0.052^{* * *} \\
(0.013)\end{array}$ \\
\hline$\beta_{G_{M}}$ & & $\begin{array}{c}0.120^{* * *} \\
(0.013)\end{array}$ & & & $\begin{array}{c}0.118^{* * *} \\
(0.015)\end{array}$ & $\begin{array}{c}0.091^{* * *} \\
(0.015)\end{array}$ \\
\hline$\beta_{C C}$ & & & $\begin{array}{c}0.013 \\
(0.031)\end{array}$ & & $\begin{array}{l}0.038^{* *} \\
(0.017)\end{array}$ & $\begin{array}{c}0.050^{* * *} \\
(0.011)\end{array}$ \\
\hline$\beta_{S}$ & & & & $\begin{array}{c}0.039 \\
(0.033)\end{array}$ & $\begin{array}{c}0.029 \\
(0.028)\end{array}$ & $\begin{array}{c}0.002 \\
(0.027)\end{array}$ \\
\hline$\mu$ & & & & & & $\begin{array}{c}-0.075^{* * *} \\
(0.017)\end{array}$ \\
\hline$\pi$ & & & & & & $\begin{array}{c}-0.052^{* * *} \\
(0.009)\end{array}$ \\
\hline Observaciones & 305 & 305 & 299 & 287 & 282 & 252 \\
\hline Estadístico F & $21.503^{* * *}$ & $79.837^{* * *}$ & 0.385 & $3.649^{*}$ & $25.562^{* * *}$ & $19.006^{* * *}$ \\
\hline $\mathrm{R}^{2}$-WITHIN & 0.074 & 0.229 & 0.001 & 0.014 & 0.296 & 0.351 \\
\hline $\mathrm{R}^{2}$ WITHIN-Ajustado & -0.046 & 0.129 & -0.131 & -0.123 & 0.186 & 0.228 \\
\hline $\mathrm{R}^{2}$-Agrupado & 0.025 & 0.135 & 0.006 & 0.0003 & 0.166 & 0.271 \\
\hline $\mathrm{R}^{2}$ Agrupado-Ajustado & 0.022 & 0.133 & 0.002 & -0.003 & 0.154 & 0.253 \\
\hline
\end{tabular}

Nota: entre paréntesis se encuentra el error estandar. Los estadísticos-t son computados usando el estimador robusto de la matriz de covarianzas de Driscoll y Kraay (1998).

${ }^{*} \mathrm{p}<0.1 ;{ }^{* *} \mathrm{p}<0.05 ;{ }^{* * *} \mathrm{p}<0.01$ 
Al observar el modelo con cuatro indicadores en la columna 5, se desprende que existe una asociación estadísticamente significativa entre las expectativas y los distintos flujos de información. Los signos de dicha asociación están en línea con los esperados. Particularmente, el indicador de cuenta corriente no solo gana significatividad estadística, sino que también relevancia económica para explicar cómo los individuos formulan sus expectativas. Si observamos más en detalle los resultados que se desprenden de dicha columna, se aprecia que un aumento de una desviación estándar en la medida de aceleración económica en el corto plazo está asociado a un aumento de $3,5 \%$ en la esperanza del indicador de expectativas económicas. Sin embargo, cuando se observa el indicador de aceleración económica de mediano plazo, el efecto de este sobre la esperanza de las expectativas aumenta significativamente. En este caso, un incremento de una desviación estándar en la medida de aceleración económica en el mediano plazo está asociado a un aumento, en promedio, de $6,4 \%$ en la diferencia de proporción de individuos entre aquellos que esperan una mejora de la performance económica futura respecto de aquellos que esperan que empeore o bien, produce un aumento de 0.26 desvíos estándar en el indicador de expectativas. De aquí se desprende que los agentes asignan una mayor importancia al indicador de aceleración de crecimiento de mediano plazo, el cual permite a los agentes incorporar información más precisa y relevante al formular sus expectativas.

Por otro lado, la columna 5 sugiere, además, que una variación positiva de un desvío estándar en el saldo del balance de cuenta corriente como porcentaje del PBI está asociado, en promedio, a un incremento de $3,6 \%$ en la proporción de individuos que espera una buena performance económica en los próximos 12 meses o bien, está asociado a un aumento de 0.14 desvíos estándar en la medida de expectativas de los individuos. Este indicador es estadísticamente significativo al $10 \%$. Esto sugiere que los agentes tienen en cuenta la dinámica del balance de cuenta corriente a la hora de formar expectativas. Como se mencionó en la sección 6.1, por un lado, este indicador parece ser relevante cuando se lo evalúa en un contexto, mientras que aisladamente no parece ser relevante. Por otro lado, la relevancia económica que adquiere este indicador puede ser explicada mediante la corrección del sesgo, generado por la correlación negativa entre el indicador de vulnerabilidad externa y el indicador de aceleración. Por último, el coeficiente del indicador de opiniones en la prensa internacional posee el signo esperado, sin embargo, dado que esta medida no es estadísticamente significativo parece indicar que los individuos no tienen en cuenta el tono de las noticias en la prensa internacional para formular sus expectativas (ver columna 5 de la tabla 3). ${ }^{44}$

Nuevamente, como se ha realizado en la sección anterior, se incorpora en este análisis dos variables de control que influyen en la dinámica económica. Dichas variables son la tasa de desempleo $(\mu)$ y la tasa de inflación $(\pi)$. Se espera que incrementos en estos indicadores estén asociados negativamente a las formulaciones de expectativas de los individuos. Los resultados de esta nueva especificación se pueden observar en la columna 6. En primer lugar, ambas variables poseen el signo esperado. En segundo lugar, bajo esta especificación, tanto la tasa de desempleo como la tasa de inflación

\footnotetext{
${ }^{44}$ Los resultados reportados en la columna 5 de la tabla 3, no varían sustancialmente cuando se regresa un modelo con igual especificación pero controlando por el rezago del indicador de expectativas, con excepción del indicador de vulnerabilidad, el cual deja de ser estadisticamente significativo.
} 
parecen no ser relevantes para explicar la evolución de la esperanza del indicador de expectativas. Por último, los coeficientes de los restantes flujos de información no presentan alteraciones considerables, manteniéndose los resultados anteriormente mencionados. $^{45} 46$

Por último, la tabla 3 reporta los test-F de significatividad conjunta de los indicadores de flujos de información y el $R^{2}-$ ajustado correspondiente a distintos modelos (within - agrupado). Respecto al primer conjunto de estadísticos, se puede inferir que los indicadores económicos en conjunto son estadísticamente significativos y, por lo tanto, pueden explicar cómo los individuos forman opiniones la performance económica futura. Respecto al segundo conjunto de estadísticos, el $R^{2}$ - ajustado del modelo within como el correspondiente al modelo agrupado (el cual que no modela la heterogeneidad por periodo y por país) parecen indicar que los indicadores objetivos y subjetivos utilizados en este trabajo contribuyen a explicar una pequeña fracción de la variabilidad del indicador de expectativas $(-1,5 \%$ y $13,2 \%$, respectivamente).

A partir de estos resultados, se puede inferir que existen asociaciones económica y estadísticamente significativas entre el arribo de información referida a los indicadores económicos y la medida de opiniones sobre el desempeño económico futuro. Por otro lado, se infiere que el conjunto de estos flujos de información explica una pequeña fracción de la variabilidad de las opiniones de los individuos referidas a las perspectivas sobre la performance económica futura. Estas conclusiones están en línea con las expuestas en el apartado 6.1 .

Una observación que corresponde destacar surge de comparar la columna 5 de la tabla 2 y 3 . Se observa que los coeficientes del modelo de evaluación del desempeño económico actual son, en magnitud, mayores a los correspondientes al modelo de expectativas sobre la performance económica. Ambos modelos intentan captar la asociación entre los flujos de información disponibles al momento de realizarse la encuesta y el proceso de formación de opiniones de los agentes respecto al desempeño económico actual o futuro. Por lo tanto, el vínculo más fuerte entre los flujos de información y las opiniones sobre la performance económica actual, es consistente con lo esperado. Resulta más fácil explicar evaluaciones de desempeño contemporáneas.

A partir de comparar la fracción de la variabilidad de las opiniones explicada por cada modelo, el $R^{2}$ - ajustado por el número de variables independientes, se puede observar que los flujos de información contribuyen en forma relativamente más importante a la capacidad del modelo para explicar la variabilidad del indicador de evaluación ${ }_{t} I_{t}$, es decir, las opiniones sobre la performance económica presente. Por ejemplo, el $R^{2}$-ajustado del modelo within pasa de $22,8 \%$ en el modelo de evaluaciones a $-1,5 \%$ en el modelo de expectativas a (ver columna 6 de la tabla 2 y 3 , respectivamente). Los valores del $R^{2}$ - ajustado son considerables en el modelo de evaluaciones si se tiene en cuenta que el modelo explica las opiniones de los individuos, las cuales pueden

\footnotetext{
${ }^{45}$ Los resultados exhibidos, a partir del modelo exhibido en la columna 5 y 6 , se mantienen cuando se excluyen los outliers o valores atípicos del indicador de expectativas. El tratamiento para los valores atípico, coincide con aquel mencionado en la sección 6.1

${ }^{46}$ Los resultados reportados en la columna 6 de la tabla 3, no varían sustancialmente cuando se regresa un modelo con igual especificación pero controlando por el rezago del indicador de expectativas. Bajo esta nueva especificación, la tasa de inflación es estadisticamente significativa al $5 \%$.
} 
Table 3: Expectativas sobre desempeño económico y flujos de información La tabla 3 reporta los coeficientes estimados del modelo:

$$
{ }_{t} I_{t+1, c}=\alpha_{t}+\alpha_{c}+\beta_{G_{C}} I_{[t-1, t] c}^{G_{C}}+\beta_{G_{M}} I_{[t-3, t] c}^{G_{M}}+\beta_{C C} I_{[t] c}^{C C}+\beta_{S} I_{[t] c}^{S}+\mu_{[t] c}
$$

La variable dependiente son las expectativas de los individuos $\left({ }_{t} I_{t+1}\right)$. Los flujos de información son capturados a traves del indicador de aceleración del crecimiento constituido para una ventana corta de tiempo $\left(\beta_{G_{C}}\right)$, el indicador de aceleración de mediano plazo $\left(\beta_{G_{M}}\right)$, el indicador de vulnerabilidad externa $\left(\beta_{C C}\right)$ y el indicador del tono en las noticias de la prensa $\left(\beta_{S}\right)$. Por ultimo, son incorparadas al análisis, la tasa de inflación $(\pi)$ y la tasa de desempleo $(\mu)$ como variables alternativas que captan las condiciones macroeconómicas. Para facilitar la comparación entre los coeficientes estimados, todas las variables explicativas han sido estandarizadas.

\begin{tabular}{|c|c|c|c|c|c|c|}
\hline & (1) & $(2)$ & (3) & (4) & (5) & (6) \\
\hline$\beta_{G_{C}}$ & $\begin{array}{c}0.042^{* * *} \\
(0.012)\end{array}$ & & & & $\begin{array}{c}0.035^{* * *} \\
(0.013)\end{array}$ & $\begin{array}{r}0.035^{* * *} \\
(0.012)\end{array}$ \\
\hline$\beta_{G_{M}}$ & & $\begin{array}{c}0.061^{* * *} \\
(0.015)\end{array}$ & & & $\begin{array}{c}0.064^{* * *} \\
(0.018)\end{array}$ & $\begin{array}{r}0.060^{* * *} \\
(0.019)\end{array}$ \\
\hline$\beta_{C C}$ & & & $\begin{array}{c}0.025 \\
(0.024)\end{array}$ & & $\begin{array}{l}0.036^{*} \\
(0.019)\end{array}$ & $\begin{array}{l}0.042^{*} \\
(0.020)\end{array}$ \\
\hline$\beta_{S}$ & & & & $\begin{array}{c}0.015 \\
(0.023)\end{array}$ & $\begin{array}{c}0.017 \\
(0.020)\end{array}$ & $\begin{array}{c}0.009 \\
(0.027)\end{array}$ \\
\hline$\mu$ & & & & & & $\begin{array}{l}-0.011 \\
(0.018)\end{array}$ \\
\hline$\pi$ & & & & & & $\begin{array}{c}-0.034 \\
(0.014)\end{array}$ \\
\hline Observaciones & 323 & 323 & 317 & 305 & 300 & 269 \\
\hline Estadístico F & $11.405^{* * *}$ & $23.739^{* * *}$ & 1.977 & 0.732 & $8.904^{* * *}$ & $6.186^{* * *}$ \\
\hline $\mathrm{R}^{2}$-WITHIN & 0.038 & 0.077 & 0.007 & 0.003 & 0.120 & 0.141 \\
\hline $\mathrm{R}^{2}$ WITHIN-Ajustado & -0.083 & -0.040 & -0.121 & -0.131 & -0.011 & -0.015 \\
\hline $\mathrm{R}^{2}$-Agrupado & 0.014 & 0.042 & 40.019 & 0.00000 & 0.076 & 0.152 \\
\hline $\mathrm{R}^{2}$ Agrupado-Ajustado & 0.011 & 0.039 & 0.016 & -0.003 & 0.063 & 0.132 \\
\hline
\end{tabular}

Nota: entre paréntesis se encuentra el error estandar. Los estadísticos-t son computados usando el estimador robusto de la matriz de covarianzas de Driscoll y Kraay (1998).

${ }^{*} p<0.1 ;{ }^{* *} p<0.05 ;{ }^{* * *} p<0.01$ 
estar influenciadas por factores no económicos (por ejemplo, inclinación política de los individuos) que difieren de las medidas de las condiciones económicas utilizadas en este trabajo. Esta relación se mantiene cuando se observa el $R^{2}$ - ajustado del modelo agrupado, es decir, el modelo que no contempla la heterogeneidad inobservable. Estos resultados denotan las dificultades asociadas a explicar la realidad y la dinámica de las opiniones en contextos de aprendizaje social.

Los modelos descriptos en el apartado 6.1 y 6.2 documentan una asociación estadísticamente significativa entre los flujos de información y la formación de opiniones de los individuos respecto al desempeño económico relativo aquel exhibido doce meses en el pasado. Los signos de las variables incorporadas en ambos modelos, responden a los esperados y su significancia económica no es depreciable. Sin embargo, en ambos modelos, el indicador que captura el tono de las opiniones en la prensa internacional parece no ser relevante para explicar la evolución de las opiniones de los individuos respecto al desempeño económico. Por último, la asociación entre los indicadores económicos y las opiniones de los individuos parece robusta al incluirse dos nuevos controles, a saber, la tasa de inflación y la tasa de desempleo.

\section{Evaluación del contenido informativo de las expectativas}

En esta sección, se evaluará la medida en que las expectativas reportadas por los individuos reflejan información sobre evaluaciones posteriores. Este ejercicio puede ser interpretado como una evaluación de la eficiencia del proceso de formación de expectativas. Un escenario en el que las expectativas reflejan toda la información disponible, es consistente con un proceso de formación de expectativas eficiente. En cambio, un escenario en el que existen datos disponibles que proveen información adicional, es consistente con ineficiencias en las expectativas. Estas ineficiencias pueden corresponder a instancias en las que información relevante no es incorporada por los individuos durante el proceso de formación de expectativas. Esto último puede observarse en presencia de individuos que poseen recursos cognitivos limitados, quienes fallan al incorporar toda la información disponible, revelando, de esta manera, que estos subreaccionan a flujos entrantes de información.

Los individuos el próximo año, reportarán cuando sean encuestados sus creencias sobre el desempeño económico contemporáneo respecto a la performance económica exhibida 12 meses en el pasado. Por lo tanto, se estiman dichas opiniones como una función de los valores rezagados de las expectativas e indicadores de la situación económica. Más específicamente, se analiza la asociación entre la evaluación contemporánea que realizan los agentes en $t+1$, con las expectativas que forman en $t \mathrm{y}$ los flujos de información en $t-1$. La restricción al conjunto de información en $t-1$, responde al objetivo de no incorporar en el análisis información que los individuos no conocían o disponían a la hora de formular un reporte subjetivo. Por lo tanto, el modelo de datos en panel es: 


$$
\begin{aligned}
{ }_{t+1} I_{t+1, c} & =\alpha_{t}+\alpha_{c}+\beta_{E t} I_{t+1, c}+\beta_{G_{C}} I_{[t-2, t-1] c}^{G_{C}},+\beta_{G_{M}} I_{[t-4, t-1] c}^{G_{M}} \\
& +\beta_{C C} I_{[t-1] c}^{C C}+\beta_{S} I_{[t-1] c}^{S}+\mu_{[t+1] c}
\end{aligned}
$$

donde $\mathrm{c}$ indica el país, $\alpha_{t}$ representa el efecto fijo por período, el cual captura shocks globales que son comunes a todos los países en cada año. El coeficiente $\alpha_{c}$, es el efecto fijo por país el cual captura características culturales e institucionales que difieren entre países, las cuales no varían en el tiempo. $\mu_{c[t]}$ es el término de error. $\beta_{G_{C}}, \beta_{G_{M}}, \beta_{C C}$ y $\beta_{S S}$, son los parámetros de interés a estimar correspondientes a cada uno de los flujos de información descriptos en la sección 3 , esto es, el indicador de aceleración de crecimiento constituido para una ventana corta de información, el propio constituido que comprar periodos más distantes de tiempo, el indicador de vulnerabilidad externa y el indicador del tono en las noticias, respectivamente. Por último, $\beta_{E}$ corresponde al coeficiente de las expectativas respecto a la performance futura de la economía, formuladas por los agentes en t. Se espera que expectativas positivas formuladas en t, anticipen una evaluación futura positiva. Bajo la hipótesis de un proceso de formación de expectativas eficiente, los flujos de información no deberían ser estadísticamente significativos. ${ }^{47} \mathrm{Sin}$ embargo, resultados que se alejen de esta premisa son consistentes con ineficiencias en el proceso de formación de expectativas. En este sentido, pueden tener lugar fenómenos de sub-reacción o sobre-reacción. Respecto a lo primero, se espera que el arribo de información positiva referida a cada uno de estos flujos de información genere un aumento en la evaluación esperada respecto a la performance económica corriente. Respecto al segundo fenómeno, se espera que el arribo de información genere una caída en la evaluación esperada respecto a la performance económica corriente, siendo consistente con respuestas individuales exageradas a ciertos flujos de información durante el proceso de formación de expectativas. Para facilitar las comparaciones de los coeficientes estimados, todas las variables explicativas han sido estandarizadas.

La tabla 4 muestra los resultados de la estimación del modelo que intenta caracterizar la relación entre la evaluación del desempeño económico futuro, los flujos de información en $t-1$ y las expectativas formuladas en t respecto a la performance económica. En primer lugar, el indicador de expectativas contribuye a anticipar la evaluación esperada, siendo consistente con lo esperado. Por otro lado, a partir de la columna 1 a 5 , se observa que al evaluarse individualmente los flujos de información, controlando por las expectativas, el indicador de aceleración conformado para una ventana más reciente, el indicador de vulnerabilidad externa y el indicador de opiniones en la prensa resultan estadísticamente significativos para explicar la evolución de las evaluaciones esperadas. Sin embargo, el indicador de aceleración constituido con información más extensa, parecen no ser flujos de información relevantes para anticipar la evaluación esperada.

Continuando con el análisis de la tabla 4, de la columna 6 se desprende similares conclusiones a las que se pudieron arribar del análisis individual de cada flujo de información, controlando por las expectativas. Cuando se analiza la asociación entre los flujos de información y las evaluaciones esperadas de los individuos, se encuentra que

\footnotetext{
${ }^{47}$ Teniendo en cuenta la estructura censurada de la información, un proceso de formación de expectativas eficiente, no implica que el coeficiente de las expectativas $\beta_{E}$ sea igual a uno.
} 
las expectativas formadas por los agentes en $\mathrm{t}$, sobre la situación económica futura, tiene una asociación positiva con la evaluación esperada de la performance económica. Se puede observar que un incremento en un desvío estándar en las expectativas sobre la situación económica futura de los individuos, anticipa un aumento de 10,5\% en la esperanza del indicador de evaluación de la performance económica en $t+1$ respecto a la performance corriente. En otras palabras, un incremento en un desvío estándar en el indicador de expectativas anticipa, en promedio, un aumento de 0.39 desvíos estándar en el indicador de evaluación. De aquí se desprende que las expectativas reportadas por los individuos contienen información respecto a las evaluaciones de desempeño futuro, es decir, las expectativas se constituyen como un buen pronóstico de las evaluaciones esperadas. Este indicador es estadísticamente significativo al $1 \%$. Este resultado es consistente con lo esperado, en el sentido de que bajo eficiencia en las expectativas no se esperaba una relación uno a uno entre las expectativas y la evaluación esperada. ${ }^{48}$

A partir de la columna 6 también se desprende que tanto el indicador de aceleración del crecimiento constituido con información más reciente, como el saldo de la cuenta corriente como porcentaje del PBI tienen una asociación estadísticamente significativa (al 5 y $1 \%$, respectivamente) con la evaluación esperada. Por un lado, un aumento de un desvío estándar en el indicador de crecimiento constituido con información más reciente está asociado a un incremento promedio de $2,9 \%$ en la esperanza del indicador de la evaluación esperada que realizarán los agentes. Por otro lado, un incremento de un desvío estándar en el saldo de cuenta corriente en $t-1$ anticipa, en promedio, un incremento de $5,1 \%$ en el indicador de la evaluación que realizaran los individuos de la performance económica en $t+1$ respecto a $t$. En otras palabras, un incremento de un desvío estándar en el saldo de cuenta corriente, en promedio, anticipa un aumenta 0.19 desvíos estándar en el indicador de evaluación. Esto nos permite inferir que el arribo de información respecto al indicador de vulnerabilidad externa y al indicador de aceleraciones en la tasa de crecimiento conformado con información de corto plazo, permiten anticipar la evaluación futura más allá de la información provista por las expectativas.

Continuando con los resultados que se exponen en la columna 6 de la tabla 4 , se puede observar que el indicador de opiniones en la prensa, bajo esta especificación, es estadísticamente significativo al $5 \%$. Esto permite inferir que dicho indicador es relevante para anticipar cómo los individuos evaluaran la performance económica en el futuro. Sin embargo, el signo de este coeficiente parece indicar cierto grado de sobre-reacción por parte de los individuos a flujos entrantes de información referidas a esta variable. Esto último denota circunstancias en que las expectativas responden excesivamente debido a una extrapolación injustificada producto de una ponderación excesiva de las noticias recientes. ${ }^{49}$

\footnotetext{
${ }^{48} \mathrm{~A}$ modo de ejercicio de robustez, se regresa el modelo propuesto en esta sección pero incorporando el indicador de expectativas al cuadrado y al cubo, es decir, se considera una relación no lineal entre el indicador de expectativas y el indicador de evaluación esperada. En ambos casos, los resultados obtenidos no varían, en términos de significatividad estadística y económica respecto de aquellos exhibidos en la tabla 4 . Además, bajo la especificación de la columna 6 de la tabla 4, tanto el indicador de expectativas al cuadrado como el indicador de expectativas al cubo, no son estadísticamente significativos.

${ }^{49}$ Ver, por ejemplo, Beshear y coautores (2003) y Mankiw, Reis y Wolfers (2004).
} 
A partir de los resultados expuestos en estos últimos párrafos, se desprende que la evaluación esperada puede ser explicada, a partir de esta especificación, por las expectativas formuladas por los agentes en $t \mathrm{y}$, además, por ciertos flujos de información en t $-1 .{ }^{50}$ Por lo tanto, la evidencia que se expone en la tabla 4 , contribuye a explicar la existencia de ineficiencias en el proceso de formación de expectativas. Por un lado, se puede inferir que las expectativas de los agentes no parecen ser un estadístico suficiente, es decir, las expectativas formadas en $t$ parecen no estar recogiendo toda la información relevante en forma adecuada, ya que existe información en $t-1$ que puede ser utilizada para mejorar los pronósticos. Por otro lado, se reporta evidencia consistente con fenómenos de sub-reacción y sobre-reacción. Respecto al primer fenómeno, el arribo de información referida al indicar de aceleración de mediano plazo y aquella relacionada al saldo de cuenta corriente, generan un aumento en la evaluación esperada. Esto último se vincula con la existencia de individuos con recursos cognitivos limitados, quienes fallan al incorporar toda la información disponible. ${ }^{51}$ Con respecto al segundo fenómeno, el arribo de información asociada a noticias recientes en la prensa genera una disminución en la evaluación esperada, indicando que los individuos extrapolaron injustificadamente información asociada a la prensa durante el proceso de formación de expectativas. La presencia de ineficiencias en dicho proceso está en línea con la evidencia reportada por Souleles (2004).

Otro resultado relevante que se desprende tanto de la columna 3,6 y 7 de la tabla 4, se refiere a que el indicador de aceleración del crecimiento constituido con información más distante, incluso cuando se lo evalúa conjuntamente, parece no ser una variable relevante para anticipar como los agentes realizarán sus evaluaciones sobre la situación económica.

Los resultados anteriormente mencionados se mantienen si incorporamos dos indicadores económicos que contribuyen a explicar la dinámica económica. Particularmente, estos son la tasa de inflación $(\pi)$ y la tasa de desempleo $(\mu)$. Los resultados se exponen en la columna 7 de la tabla 4 . Como puede observarse, el arribo de información en $t-1$ relacionada a estos dos indicadores parece no ser relevante para anticipar cómo evaluaran los individuos la performance economía en $t+1$. Por último, bajo esta nueva especificación el signo del indicador de opiniones en la prensa continúa siendo consistente con sobre-reacción por parte de los individuos. ${ }^{52}$

\footnotetext{
${ }^{50}$ En el Apéndice C, se realiza una nueva estimación de la asociación entre la evaluación esperada y los flujos de información en $t-1$, sin controlar por el indicador de expectativas

${ }^{51}$ Ver, por ejemplo, Sims (2003), Woodford (2001) y Coibon y Gorodnichenko (2015).

${ }^{52}$ Los modelos bajo la especificación propuesta en la columna 6 y 7 , fueron analizados al excluirse los outliers o valores atípicos del indicador de evaluación esperada. Respecto al tratamiento de estos últimos, se realizaron tres ejercicios: $i$ ) se regresó el mismo modelo pero excluyendo el valor mínimo y el valor máximo de la medida de evaluación esperada. Los resultados hallados, se mantienen; $i i$ ) se estimó el modelo excluyendo aquellas observaciones que se encuentran arriba del percentil 99 y por debajo del primer percentil del indicador de evaluación esperada. Respecto al modelo especificado en la columna 5, los resultados se mantienen, sin embargo, el indicador de opiniones en la prensa deja de ser estadísticamente significativo. Cuando se regresa el modelo exhibido en la columna 6 , el indicador de aceleración de crecimiento de corto plazo deja de ser estadísticamente significativo, mientras que el indicador de opiniones en la prensa lo es al $10 \%$; iii) se estimó el modelo excluyendo aquellas observaciones que se encuentran por debajo del percentil 5 y por encima del percentil 95 del indicador de evaluación esperada. Los resultados se mantienen bajo la especificación del modelo sin incluir la tasa de desempleo e inflación. Al incluirse estos dos últimos indicadores, el indicador de aceleración de corto
} 
Por último, en la tabla 4 se reportan los estadísticos test-F de significatividad conjunta y el coeficiente de determinación correspondiente a los modelos within y agrupado. Respecto al primer estadístico, se puede inferir que todas variables son estadísticamente significativas en conjunto para anticipar cómo los agentes evaluaran la performance económica, indicando que las expectativas no han incorporado adecuadamente la información disponible reciente. Por otro lado, al observar la fracción de la variabilidad de las opiniones esperadas explicada por este modelo, el $R^{2}-$ ajustado del modelo within, igual a $11 \%$ (ver columna 7), contribuye a explicar una relativa baja proporción de la variabilidad de dicha variable. Sin embargo, este estadístico aumenta considerablemente cuando se regresa el modelo sin tener en cuenta la heterogeneidad por país y por individuo, es decir, el $R^{2}$ - ajustado de un modelo agrupado, el cual asciende a $36,3 \%$ (ver columna 7 ).

\section{Asociación entre opiniones y las características sociode- mográficas de los individuos.}

La heterogeneidad en las creencias entre los individuos puede explicarse a partir de que éstos poseen desatención racional -falta de atención por motivos racionales- producto de que sólo incorporan parte de información debido a que adquirir y procesar dicha información es costoso (Mankiw, Reis y Wolfers, 2003; Carroll, 2003), o bien, como argumentan Malmendier y Nagel (2013), los agentes utilizan información derivada de su experiencia personal, la cual puede ser muy variable e imprecisa.

Con el fin de explorar la existencia o no de heterogeneidad en las creencias, se incorpora al análisis información disponible en las encuestas referida a variables sociodemográficas de la población. Particularmente, información referida al nivel educativo y la edad de los individuos. La existencia de heterogeneidad es consistente con ponderaciones asimétricas por parte de los individuos a los distintos flujos entrantes de información.

Esta sección se vincula, por un lado, con la evidencia reportada por Das, Kuhnen y Nagel (2017), quienes encuentran que la heterogeneidad en las expectativas macroeconómicas individuales están asociadas con su estatus socioeconómico y, por otro lado, con la evidencia hallada por Malmendier y Nagel (2013), quienes, a su vez, encuentran que los individuos, cuando forman sus expectativas macroeconómicas, asignan una ponderación mayor a información referida a realizaciones macroeconómicas que han experimentado a lo largo de su vida respecto a otra información histórica disponible, es decir, que las expectativas dependen de la historia. Por su parte, Brown y Taylor (2006) encuentran que las expectativas de los individuos están influenciadas por el ciclo de vida -individuos más jóvenes son más optimistas financieramente- y el ciclo económico -los individuos son más pesimistas financieramente durante recesiones.

En las siguientes subsecciones vamos a desarrollar el modelo econométrico que describimos en la sección 7 , teniendo en cuenta algunas características demográficas de

plazo deja de ser estadísticamente significativo. 
Tabla 4: Evaluación del contenido informativo de las expectativas

La tabla 4 reporta los coeficientes estimados del modelo:

$$
\begin{aligned}
{ }_{t+1} I_{t+1, c} & =\alpha_{t}+\alpha_{c}+\beta_{E t} I_{t+1 ; c}+\beta_{G_{C}} I_{[t-2, t-1] c}^{G_{C}}+\beta_{G_{M}} I_{[t-4, t-1] c}^{G_{M}} \\
& +\beta_{C C} I_{[t-1] c}^{C C}+\beta_{S} I_{[t-1] c}^{S}+\mu_{[t+1] c}
\end{aligned}
$$

La variable dependiente son las evaluaciones esperadas de los individuos $\left({ }_{t+1} I_{t+1}\right)$. Los flujos de información son capturados a traves del indicador de aceleración del crecimiento constituido para una ventana corta de tiempo $\left(\beta_{G_{C}}\right)$, el indicador de aceleración de mediano plazo $\left(\beta_{G_{M}}\right)$, el indicador de vulnerabilidad externa $\left(\beta_{C C}\right)$ y el indicador del tono en las noticias de la prensa $\left(\beta_{S}\right)$. Ademas, las expectativas formuladas por los individuos $\left(\beta_{E}\right)$ son una variable explicativa en este modelo. Por último, son incorparadas al análisis, la tasa de inflación $(\pi)$ y la tasa de desempleo $(\mu)$ como variables alternativas que captan las condiciones macroeconómicas. Para facilitar la comparación entre los coeficientes estimados,

\begin{tabular}{|c|c|c|c|c|c|c|c|}
\hline & $(1)$ & $(2)$ & (3) & $(4)$ & (5) & (6) & $(7)$ \\
\hline$\beta_{E}$ & $\begin{array}{c}0.123^{* * *} \\
(0.030)\end{array}$ & $\begin{array}{c}0.113^{* * *} \\
(0.027)\end{array}$ & $\begin{array}{c}0.120^{* * *} \\
(0.028)\end{array}$ & $\begin{array}{c}0.115^{* * *} \\
(0.027)\end{array}$ & $\begin{array}{c}0.120^{* * *} \\
(0.029)\end{array}$ & $\begin{array}{c}0.105^{* * *} \\
(0.024)\end{array}$ & $\begin{array}{c}0.109^{* * *} \\
(0.023)\end{array}$ \\
\hline$\beta_{G_{C}}$ & & $\begin{array}{l}0.031^{* *} \\
(0.014)\end{array}$ & & & & $\begin{array}{l}0.029^{* *} \\
(0.012)\end{array}$ & $\begin{array}{l}0.028^{* *} \\
(0.012)\end{array}$ \\
\hline$\beta_{G_{M}}$ & & & $\begin{array}{c}0.001 \\
(0.022)\end{array}$ & & & $\begin{array}{c}0.004 \\
(0.022)\end{array}$ & $\begin{array}{l}0.0003 \\
(0.018)\end{array}$ \\
\hline$\beta_{C C}$ & & & & $\begin{array}{c}0.064^{* * *} \\
(0.020)\end{array}$ & & $\begin{array}{c}0.051^{* * *} \\
(0.019)\end{array}$ & $\begin{array}{c}0.055^{* * *} \\
(0.021)\end{array}$ \\
\hline$\beta_{S}$ & & & & & $\begin{array}{c}-0.057^{* * *} \\
(0.019)\end{array}$ & $\begin{array}{c}-0.036^{* *} \\
(0.018)\end{array}$ & $\begin{array}{r}-0.028^{*} \\
(0.016)\end{array}$ \\
\hline$\mu$ & & & & & & & $\begin{array}{c}0.011 \\
(0.034)\end{array}$ \\
\hline$\pi$ & & & & & & & $\begin{array}{l}-0.005 \\
(0.016) \\
\end{array}$ \\
\hline Observaciones & 236 & 235 & 235 & 236 & 226 & 225 & 206 \\
\hline Estadístico F & $56.194^{* * *}$ & $28.878^{* * *}$ & $26.8 \$ 1^{* * *}$ & $33.968^{* * *}$ & $30.405^{* * *}$ & $13.261^{* * *}$ & $8.912^{* * *}$ \\
\hline $\mathrm{R}^{2}-$ WITHIN & 0.216 & 0.222 & 0.205 & 0.251 & 0.240 & 0.260 & 0.271 \\
\hline $\mathrm{R}^{2}$ WITHIN-Ajustado & 0.097 & 0.099 & 0.079 & 0.133 & 0.114 & 0.123 & 0.110 \\
\hline$R^{2}$-Agrupado & 0.298 & 0.324 & 0.299 & 0.323 & 0.303 & 0.360 & 0.385 \\
\hline $\mathrm{R}^{2}$ Agrupado-Ajustado & 0.295 & 0.318 & 0.293 & 0.317 & 0.296 & 0.345 & 0.363 \\
\hline
\end{tabular}
todas las variables explicativas han sido estandarizadas.

Nota: entre paréntesis se encuentra el error estandar. Los estadísticos-t son computados usando el estimador robusto de la matriz de covarianzas de Driscoll y Kraay (1998). 
la población.

\subsection{Nivel educativo}

Como argumentan Das, Kuhnen y Nagel (2017), la heterogeneidad en las expectativas macroeconómicas individuales está asociada con su estatus socioeconómico. Estos autores evidencian que las expectativas macroeconómicas individuales están influenciadas por los cambios recientes en las circunstancias económicas personales que estos individuos han percibido. En base a estos antecedentes, se intenta identificar si existe evidencia que sea consistente con ponderaciones asimétrica de los flujos entrantes de información por parte de individuos con diferentes niveles educativos. Un resultado positivo es consistente con heterogeneidad en el proceso de formación de opiniones respecto al desempeño económico.

A partir de los microdatos de la encuesta que realiza Latinobarómetro, es posible realizar el mismo análisis llevado a cabo en la sección 7 pero teniendo en cuenta la información referida al nivel educativo de los individuos. Con este objetivo, se agrupó a los encuestados según su nivel educativo en tres grupos: $i$ ) nivel educativo bajo (NEB): analfabeto, básica incompleta y básica completa; $i$ ) nivel educativo medio (NEM): secundaria, media y técnica incompleto y secundaria, media y técnica completo; y iii) nivel educativo alto (NEA): superior incompleto y superior completo. ${ }^{53}$ Por lo tanto, esto permite analizar si las expectativas de los agentes, que poseen un determino nivel educativo, contribuyen a anticipar cómo será la evaluación esperada del conjunto total de los encuestados. ${ }^{54}$

A partir de los resultados expuestos en la tabla 5 , se concluye que, al igual que en la sección 7, independientemente del nivel educativo del encuestado, la evolución de las evaluaciones esperadas de estos, solo puede ser explicada por sus expectativas formuladas en t y la información disponible en t-1. En particular, información asociada al indicador de aceleración del crecimiento de corto plazo, el indicador de vulnerabilidad externa y el indicador de opiniones en la prensa, permiten anticipar evaluaciones futuras. Por otro lado, se encuentra que la ponderación asignada a estos tres flujos de información es similar entre individuos con diferente nivel educativos (a su vez, estos coeficientes son similares a los hallados para el promedio de los encuestados; resultados expuestos en la tabla 4).

Por lo tanto, bajo esta especificación, se puede concluir que tanto las expectativas

\footnotetext{
${ }^{53}$ Se arriba a similares resultados si la forma de agrupación es: $i$ ) nivel educativo bajo (NEB): analfabeto y básica incompleta; $i i$ ) nivel educativo medio (NEM): básica completa, secundaria, media y técnica incompleto y secundaria, media y técnica completo, superior incompleto; y $i$ ii) nivel educativo alto (NEA): superior completo.

${ }^{54}$ Se ha realizado una pequeña modificación en este apartado respecto al modelo desarrollado en la sección 7. Para poder comparar los coeficientes entre los diferentes grupos según su nivel educativo, se construyó la expectativa $\left({ }_{t} I_{t+1}\right)$ correspondiente a cada grupo según nivel educativo, pero mantenido la evaluación esperada $\left({ }_{t+1} I_{t+1}\right)$ del conjunto de todos los individuos. Esto permite analizar si las expectativas de los agentes que pertenecen a un determino grupo que posee cierto nivel educativo, contribuyen a anticipar cómo será la evaluación esperada del conjunto total de los encuestados.

Se arriba a similares resultados al estimar el modelo desarrollado en la sección 7 pero manteniendo el indicador de evaluación esperada $\left({ }_{t+1} I_{t+1}\right)$ correspondiente a cada grupo.
} 
como ciertos flujos de información, contribuyen a anticipar cómo los agentes con diferentes niveles educativos evaluarán el desempeño económico en $t+1$. Además, de la tabla 5 se deprende que, al igual que en la sección 7, las expectativas no parecen estar recogiendo toda la información relevante en forma adecuada, ya que existe información en $t-1$ que puede ser utilizada para mejorar los pronósticos. Estos resultados evidencian la existencia de ineficiencias en el proceso de formación de expectativas. Una fuente de dicha ineficiencia se asocia a fenómenos de sub-reacción, es decir, la existencia de individuos con recursos cognitivos limitados, quienes fallan al incorporar toda la información disponible. En particular, el arribo de información asociada al indicador de vulnerabilidad externa y el indicador de aceleración de corto plazo, generan un aumento en la evaluación esperada. ${ }^{55}$

Por último, de la tabla 5 se desprende que el indicador de opiniones en la prensa internacional es relevante para anticipar como los individuos, independientemente de su nivel educativo, evaluaran la performance económica. Sin embargo, el signo del coeficiente evidencia cierto grado de sobre-reacción a los flujos entrantes de información referidos a esta variable. Esto denota circunstancias en que las expectativas responden excesivamente debido a una extrapolación injustificada o respuestas indebidas a noticias entrantes producto de una ponderación excesiva de la experiencia reciente. ${ }^{56}$ Este resultado está en línea con aquel obtenido para el promedio de los individuos, expuesto en la tabla 4. Por lo tanto, se evidencia otra fuente de ineficiencia en el proceso de formación de expectativas asociada a fenómenos de sobre-reacción.

En función de los resultados obtenidos en esta subsección, se puede inferir que no existe evidencia de ponderación asimétrica a flujos de información por parte de los individuos con diferentes niveles educativos. ${ }^{57}$ Esta evidencia contrasta con lo hallado por Brown y Taylor (2006) y Das, Kuhnen y Nagel (2017). Por otro lado, estos resultados aportan cierta robustez a los resultados obtenidos en la sección 7, particularmente respecto a la existencia de ineficiencias en el proceso de formación de expectativas y la existencia de individuos con recursos cognitivos limitados quienes sub-reaccionan a ciertos flujos de información. Además, esta subsección evidencia la existencia de sobre-reacción por parte de los individuos a flujos de información provenientes de la prensa. Por último, los resultados de esta subsección son robustos, siendo consistente con lo esperado, cuando el análisis se extiende para incorporar todos los niveles educativos. Estos resultados se exponen en el Apéndice D.

\subsection{Edad}

Como se mencionó anteriormente, Malmendier y Nagel (2013) evidencian que los individuos asignan, al formar las expectativas macroeconómicas, una mayor ponderación a las realizaciones de datos macroeconómicos experimentados durante sus tiempos de vida en comparación con otros datos históricos disponibles. Bajo esta especificación estos autores argumentan, por un lado, que las expectativas dependen de la historia:

\footnotetext{
${ }^{55}$ Ver, por ejemplo, Sims (2003), Woodford (2001) y Coibon y Gorodnichenko (2015).

${ }^{56}$ Ver, por ejemplo, Beshear y coautores (2003) y Mankiw, Reis y Wolfers (2004).

${ }^{57}$ Estos resultados se mantienen cuando se regresa el modelo con igual especificacion pero teniendo en cuenta todos los individuos y se controlando por las heterogeneidades no observadas asociadas a cada grupo educativo, las cuales no varian en el tiempo.
} 
Table 5: Modelo descriptivo de las evaluaciones esperadas según el nivel educativo de los individuos

La tabla 5 reporta los coeficientes estimados del modelo:

$$
\begin{aligned}
{ }_{t+1} I_{t+1, c} & =\alpha_{t}+\alpha_{c}+\beta_{E t} I_{t+1 ; c}+\beta_{G_{C}} I_{[t-2, t-1] c}^{G_{C}}+\beta_{G_{M}} I_{[t-4, t-1] c}^{G_{M}} \\
& +\beta_{C C} I_{[t-1] c}^{C C}+\beta_{S} I_{[t-1] c}^{S}+\mu_{[t+1] c}
\end{aligned}
$$

La variable dependiente son las evaluaciones esperadas de los individuos $\left({ }_{t+1} I_{t+1}\right)$. Los flujos de información son capturados a traves del indicador de aceleración del crecimiento constituido para una ventana corta de tiempo $\left(\beta_{G_{C}}\right)$, el indicador de aceleración de mediano plazo $\left(\beta_{G_{M}}\right)$, el indicador de vulnerabilidad externa $\left(\beta_{C C}\right)$ y el indicador del tono en las noticias de la prensa $\left(\beta_{S}\right)$. Ademas, las expectativas formuladas por los individuos $\left(\beta_{E}\right)$ son una variable explicativa en este modelo. Por último, son incorparadas al análisis, la tasa de inflación $(\pi)$ y la tasa de desempleo $(\mu)$ como variables alternativas que captan las condiciones macroeconómicas.

Se agrupo a los encuestados según su nivel educativo: se agrupó a los encuestados según su nivel educativo, en tres grupos: $i$ ) nivel educativo bajo (NEB): analfabeto, básica incompleta y básica completa; $i i$ ) nivel educativo medio (NEM): secundaria, media y técnica incompleto y secundaria, media y técnica completo; y iii) nivel educativo alto (NEA): superior incompleto y superior completo.

\begin{tabular}{lccc}
\hline \hline & {$[\mathrm{NEB}]$} & {$[\mathrm{NEM}]$} & {$[\mathrm{NEA}]$} \\
\hline$\beta_{E}$ & $0.095^{* * *}$ & $0.109^{* * *}$ & $0.088^{* * *}$ \\
& $(0.026)$ & $(0.024)$ & $(0.021)$ \\
& & & \\
$\beta_{G_{C}}$ & $0.031^{* *}$ & $0.028^{* *}$ & $0.030^{* *}$ \\
& $(0.012)$ & $(0.012)$ & $(0.013)$ \\
& & & \\
$\beta_{G_{M}}$ & 0.005 & 0.002 & 0.017 \\
& $(0.023)$ & $(0.022)$ & $(0.025)$ \\
& & & \\
$\beta_{C C}$ & & & \\
& $0.052^{* * *}$ & $0.049^{* * *}$ & $0.068^{* * *}$ \\
& $(0.019)$ & $(0.018)$ & $(0.020)$ \\
$\beta_{S}$ & & & \\
& $-0.035^{*}$ & $-0.035^{* *}$ & $-0.037^{*}$ \\
& $(0.019)$ & $(0.017)$ & $(0.020)$ \\
& & & \\
\hline Observaciones & 2253 & 225 & 212 \\
Estadístico F & $11.381^{* * *}$ & $13.585^{* * *}$ & $11.120^{* * *}$ \\
$\mathrm{R}^{2}$-WITHIN & 0.231 & 0.264 & 0.240 \\
$\mathrm{R}^{2}$ WITHIN-Ajustado & 0.089 & 0.128 & 0.089 \\
\hline \hline
\end{tabular}

Nota: entre paréntesis se encuentra el error estandar. Los estadísticos-t son computados usando el estimador robusto de la matriz de covarianzas de Driscoll y Kraay (1998). ${ }^{*} \mathrm{p}<0.1 ;{ }^{* *} \mathrm{p}<0.05 ;{ }^{* * *} \mathrm{p}<0.01$ 
cohortes que han experimentado periodos de elevada inflación a lo largo de su vida, poseen expectativas inflacionarias mayores que aquellos individuos que han experimentado periodos de baja inflación. Por otro lado, también argumentan que las expectativas son heterogéneas: individuos jóvenes ponderan más la información reciente respecto a los individuos adultos, por lo tanto, diferentes generaciones tienden a estar en desacuerdo respecto a sus expectativas macroeconómicas, en particular, respecto sus expectativas inflacionarias. Por lo tanto, encuentran una asociación entre la historia macroeconómica que las cohortes de individuos han experimentado y sus expectativas.

En línea con esto, Brown y Taylor (2006) mediante el uso de encuestas de hogares de Reino Unido, evidencian que las predicciones de los individuos están influenciadas por el ciclo de vida. En particular, encuentran que individuos más jóvenes son financieramente más optimistas respecto de aquellos individuos de mayor edad.

Teniendo en cuenta los aportes de Brown y Taylor (2006) y Malmendier y Nagel (2013), en esta subsección se incorpora al análisis información referida a la edad de los individuos con el objetivo de testear si existe o no, evidencia estadísticamente significativa de ponderaciones asimétricas a flujos entrantes de información por parte de individuos de distintas edades. Un resultado positivo es consistente con heterogeneidad en las creencias respecto al desempeño económico entre individuos de diferentes edades.

En este apartado se desarrolla el modelo llevado a cabo en la sección 7 pero, en este caso, se agrupa a los individuos en dos grupos según su edad: $i$ ) adultos: aquellos encuestados cuya edad es mayor o igual a 30 años y $i$ i) jóvenes: individuos con una edad menor o igual a 29 años. ${ }^{58}$ Por lo tanto, calculamos ${ }_{t} I_{t+1}$ para cada uno de los grupos.

En la tabla 6 , se exponen los resultados de analizar cómo los agentes evaluarán la performance económica en $t+1$, pero teniendo en cuenta la edad de los encuestados. La tabla 6 evidencia similares resultados a los obtenidos en la sección 7. ${ }^{59}$ Por un lado, se encuentra que el proceso de formación de expectativas no está capturando toda la información relevante, ya que, existe información relevante en $t-1$, positiva, que anticipa cómo los agentes evaluaran la performance económica. Particularmente, solo la información referida al indicador de vulnerabilidad económica, el indicador de aceleración del crecimiento de corto plazo y la medida que captura las opiniones en la prensa, son flujos de información estadísticamente significativos. Estos resultados, nuevamente, evidencian la existencia de individuos con recursos cognitivos limitados quienes fallan al incorporar toda la información disponible durante el proceso de formación de expectativas. Esto último es consistente con agentes que sub-reaccionan ciertos flujo entrantes de información. Por lo tanto, existe evidencia de ineficiencia en el proceso de formación de expectativas, aun teniendo en cuenta individuos que pertenecen a distintos grupos etarios.

\footnotetext{
${ }^{58}$ Se arriba a similares resultados si la forma de agrupación es: $i$ ) individuos con edad menor estricta a 40 años; $i$ i) individuos cuya edad este en 40 y 60 años; y iii) individuos con edad mayor estricta a 60 años.

${ }^{59} \mathrm{Al}$ igual que en la subsección 8.1, se construye el indicador de expectativas para cada grupo etario, pero manteniendo la evaluación esperada del conjunto de todos los individuos. Se arriba a similares resultados cuando se analizan las asociaciones entre estos indicadores y aquellas evaluaciones construidas para cada grupo etario.
} 
Por otro lado, en línea con lo hallado para el promedio de todos los individuos, los resultados de la tabla 6 indican que tanto adultos como jóvenes sobre-reaccionan a la información proveniente del indicador de opiniones en la prensa. Esto último, evidencia otra fuente de ineficiencia en el proceso de formación de expectativas.

Teniendo en cuenta los resultados que se exponen en esta subsección, se puede inferir que no existe evidencia estadísticamente significativa de ponderación asimétrica a flujos de información por parte de los individuos que perecen a distinto grupo etario. ${ }^{60}$ Esta evidencia contrasta con lo hallado por Brown y Taylor (2006). Nuevamente, estos resultados aportan cierta robustez a los resultados que se obtienen en la sección 7, particularmente respecto a la existencia de ineficiencias en el proceso de formación de expectativas y la existencia de individuos con recursos cognitivos limitados que sub-reaccionan al ingreso de ciertos flujos de información. Por último, se puede inferir que los individuos, independientemente de su pertenencia a un grupo etario, sobrereaccionan a los flujos de información provenientes de la prensa.

\section{Asociación entre opiniones e identificación política de los individuos}

Huberman y coautores (2018), combinando datos de encuestas -utilizando la plataforma Pollfish y el portal MSN-y búsquedas en internet -utilizando Bing Search- comparan los estados de actitudes de los encuestados con sus comportamientos actuales. Encuentran que los encuestados que se asocian con el partido político ganador, aumentan sustancialmente sus expectativas respecto al mercado de valores y el bienestar de su familia -indicando cambios en sus actitudes. Sin embargo, estas expectativas económicas optimistas no se manifiestan en sus comportamientos actuales (revelado por su comportamiento de búsquedas en internet). Por otro lado, aquellos encuestados que se identifican con el partido político perdedor, se vuelven más pesimistas. Estos, en línea con sus expectativas económicas, disminuyeron sus búsquedas en internet relacionadas a compras de bienes durables.

Teniendo en cuenta la baja capacidad que tienen los modelos propuestos para explicar la variabilidad de las opiniones de los individuos, tiene sentido intentar corregir la medida de opiniones. En otras palabras, existe una elevada fracción de la variabilidad de las opiniones no explicado por noticias económicas. Por lo tanto, una alternativa es internar eliminar la variabilidad explicada por cuestiones política. En este sentido, una alternativa en pos de lograr aumentar la capacidad explicativa del modelo propuesto, está asociada a prescindir de las personas que están motivadas políticamente, es decir, prescindir de quienes informan una fuerte inclinación política en este conjunto de encuestas. Una posible conjetura es que el $R^{2}$ va a aumentar. Por lo tanto, en este apartado se desarrolla el modelo expuesto en la sección 7 pero prescindiendo de aquellos individuos partidarios que poseen una inclinación política fuerte, con el objetivo de analizar si nuestro ejercicio es robusto y los resultados se mantienen.

\footnotetext{
${ }^{60}$ Estos resultados se mantienen cuando se regresa el modelo con igual especificacion pero teniendo en cuenta a todos los individuos y se controlando por las heterogeneidades no observadas asociadas a cada grupo etario, las cuales no varian en el tiempo.
} 
Table 6: Modelo descriptivo de las evaluaciones esperadas según la edad de los individuos La tabla 6 reporta los coeficientes estimados del modelo:

$$
\begin{aligned}
{ }_{t+1} I_{t+1, c} & =\alpha_{t}+\alpha_{c}+\beta_{E t} I_{t+1 ; c}+\beta_{G_{C}} I_{[t-2, t-1] c}^{G_{C}}+\beta_{G_{M}} I_{[t-4, t-1] c}^{G_{M}} \\
& +\beta_{C C} I_{[t-1] c}^{C C}+\beta_{S} I_{[t-1] c}^{S}+\mu_{[t+1] c}
\end{aligned}
$$

La variable dependiente son las evaluaciones esperadas de los individuos $\left({ }_{t+1} I_{t+1}\right)$. Los flujos de información son capturados a traves del indicador de aceleración del crecimiento constituido para una ventana corta de tiempo $\left(\beta_{G_{C}}\right)$, el indicador de aceleración de mediano plazo $\left(\beta_{G_{M}}\right)$, el indicador de vulnerabilidad externa $\left(\beta_{C C}\right)$ y el indicador de sentimiento $\left(\beta_{S}\right)$. Ademas, las expectativas formuladas por los individuos $\left(\beta_{E}\right)$ son una variable explicativa en este modelo. Por último, son incorparadas al análisis, la tasa de inflación $(\pi)$ y la tasa de desempleo $(\mu)$ como variables alternativas que captan las condiciones macroeconómicas.

Se agrupo a los encuestados según su edad: se agrupó a los encuestados según su edad, en dos grupos: $i$ ) Adultos: aquellos encuestados cuya edad es mayor o igual a 30 años y ii) Jóvenes: individuos con una edad menor o igual a 29 años.

\begin{tabular}{lcc}
\hline \hline & [Jóvenes] & [Adultos] \\
\hline$\beta_{E}$ & $0.107^{* * *}$ & $0.103^{* * *}$ \\
& $(0.026)$ & $(0.023)$ \\
$\beta_{G_{C}}$ & & \\
& $0.029^{* *}$ & $0.029^{* *}$ \\
& $(0.011)$ & $(0.013)$ \\
$\beta_{G_{M}}$ & & \\
& 0.005 & 0.005 \\
$\beta_{C C}$ & $(0.022)$ & $(0.022)$ \\
& & \\
& $0.055^{* * *}$ & $0.050^{* * *}$ \\
$\beta_{S}$ & $(0.018)$ & $(0.019)$ \\
& & \\
& $-0.037^{* *}$ & $-0.035^{*}$ \\
& $(0.017)$ & $(0.018)$ \\
Observaciones & & \\
F Statistic & 225 & 225 \\
$R^{2}$-WITHIN & 0.255 & 0.257 \\
$R^{2}$ WITHIN-Ajustado & 0.117 & 0.119 \\
\hline \hline
\end{tabular}

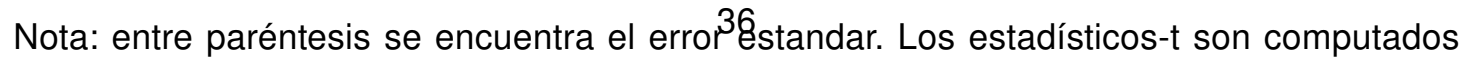
usando el estimador robusto de la matriz de covarianzas de Driscoll y Kraay (1998). ${ }^{*} \mathrm{p}<0.1 ;{ }^{* *} \mathrm{p}<0.05 ;{ }^{* * *} \mathrm{p}<0.01$ 
A través de la encuesta que realiza Latinobarómetro se vincula las inclinaciones políticas de los encuestados y sus opiniones respecto al desempeño económico. En este sentido, se utiliza la pregunta "En política se habla normalmente de ïzquierdaz "derecha". En una escala donde "1" es la izquierda y "10" la derecha, ¿dónde se ubicaría Ud.?". Por lo tanto, este apartado se concentra en las opiniones de aquellos individuos cuya respuesta se ubicó entre 4 y $6 .{ }^{61}$ Por lo tanto, calculamos ${ }_{t} I_{t+1}$ para estos individuos.

En la tabla 7 , se exponen los resultados de analizar cómo los agentes evaluarán la performance económica en $t+1$, pero teniendo en cuenta aquellos individuos que no poseen una inclinación política fuerte. La tabla 7 permite inferir que los resultados obtenidos en la sección 7 son robustos. ${ }^{62}$ Dichos resultados evidencian que el proceso de formación de expectativas no está capturando de manera adecuada toda la información relevante. Particularmente, solo la información referida al indicador de vulnerabilidad económica, el indicador de aceleración del crecimiento de corto plazo y el indicador de opiniones en la prensa, son flujos de información relevantes en $t-1$ que anticipan cómo los agentes evaluarán la performance económica. Esto último permite inferir, aun cuando se excluyen del análisis a aquellos individuos con una identificación política fuerte, la existencia de ineficiencias en el proceso de formación de expectativas y la presencia de individuos con recursos cognitivos limitados quienes no incorporan toda la información disponible durante el proceso de formación de expectativas, siendo consistente con agentes que sub-reaccionan a ciertos flujo entrantes de información.

Por otro lado, en línea con los resultados que se exhibieron para el promedio de todos los individuos, la evidencia reportada en la tabla 7 indica que los individuos sin una inclinación política fuerte, sobre-reaccionan a la información proveniente del indicador de opiniones en la prensa, siendo este indicador estadísticamente significativo al $5 \%$. Este resultado es consistente con la existencia de otra fuente de ineficiencia en el proceso de formación de expectativas.

Sin embargo, observando el coeficiente de determinación expuesto en la tabla 7 se observa que éste se encuentra en niveles similares a los expuestos en la tabla 4 de la sección 7. Por lo tanto, este resultado sugiere que aun prescindiendo de aquellos individuos que comunican una inclinación política fuerte, los indicadores económicos utilizados en este trabajo, tienen una capacidad explicativa pequeña sobre la evolución del indicador de evaluaciones esperadas. En otras palabras, la exclusión del análisis de este conjunto de individuos no permite disminuir la fracción explicada por el arribo

\footnotetext{
${ }^{61}$ La elección de estos parámetros responde a que el primer cuartil de la variable, construida a partir de la información derivada de la pregunta sobre inclinación política, es 3 y el tercer cuartil de la misma es 7.

${ }^{62} \mathrm{Al}$ igual que en la subsección 8.1 , se ha realizado una pequeña modificación en este apartado respecto al modelo desarrollado en la sección 7. Para poder comparar los coeficientes entre los diferentes grados de identificación política, se construyó la expectativa $\left({ }_{t} I_{t+1}\right)$ correspondiente a cada grupo según su respuesta, pero mantenido la evaluación esperada $\left({ }_{t+1} I_{t+1}\right)$ del conjunto de todos los individuos. Por lo tanto, esto permite analizar si las expectativas de los agentes que poseen una determinada identificación política contribuyen a anticipar cómo será la evaluación esperada del conjunto total de los encuestados.

Se arriba a similares resultados al estimar el modelo desarrollado en la sección 7 pero manteniendo el indicador de evaluación esperada $\left({ }_{t+1} I_{t+1}\right)$ correspondiente a cada grupo. Sin embargo, el indicador del tono de las noticias en la prensa deja de ser estadísticamente significativo.
} 
no asociadas a noticias económicas de la variabilidad de las opiniones. Este resultado denota las dificultades asociadas a modelar la dinámica de las opiniones de los individuos. ${ }^{63}$

\footnotetext{
${ }^{63} \mathrm{~A}$ modo de ejercicio de robustez, se regresó el modelo propuesto en esta sección, pero sólo teniendo en cuenta aquellos individuos que comunican una débil motivación política, es decir, aquellos encuestados que han valorado con 5 su inclinación política. Los resultados exhibidos en esta sección se mantienen, con la excepción de que el indicador del tono de las noticias en la prensa deja de ser estadísticamente significativo.
} 
Table 7: Modelo descriptivo de las evaluaciones esperadas según la identificación política de los individuos

La tabla 7 reporta los coeficientes estimados del modelo:

$$
\begin{aligned}
{ }_{t+1} I_{t+1, c} & =\alpha_{t}+\alpha_{c}+\beta_{E t} I_{t+1 ; c}+\beta_{G_{C}} I_{[t-2, t-1] c}^{G_{C}}+\beta_{G_{M}} I_{[t-4, t-1] c}^{G_{M}} \\
& +\beta_{C C} I_{[t-1] c}^{C C}+\beta_{S} I_{[t-1] c}^{S}+\mu_{[t+1] c}
\end{aligned}
$$

La variable dependiente son las evaluaciones esperadas de los individuos $\left({ }_{t+1} I_{t+1}\right)$. Los flujos de información son capturados a traves del indicador de aceleración del crecimiento constituido para una ventana corta de tiempo $\left(\beta_{G_{C}}\right)$, el indicador de aceleración de mediano plazo $\left(\beta_{G_{M}}\right)$, el indicador de vulnerabilidad externa $\left(\beta_{C C}\right)$ y el indicador de sentimiento $\left(\beta_{S}\right)$. Ademas, las expectativas formuladas por los individuos $\left(\beta_{E}\right)$ son una variable explicativa en este modelo. Por último, son incorparadas al análisis, la tasa de inflación $(\pi)$ y la tasa de desempleo $(\mu)$ como variables alternativas que captan las condiciones macroeconómicas.

Se agrupo a los encuestados según su identificación política prescindiendo de aquellos individuos que admiten una inclinación política fuerte.

\begin{tabular}{lc}
\hline \hline & {$[1]$} \\
\hline$\beta_{E}$ & $0.105^{* * *}$ \\
& $(0.024)$ \\
& \\
$\beta_{G_{C}}$ & $0.032^{* * *}$ \\
& $(0.012)$ \\
& \\
$\beta_{G_{M}}$ & 0.004 \\
& $(0.022)$ \\
$\beta_{C C}$ & $0.049^{* * *}$ \\
& $(0.019)$ \\
$\beta_{S}$ & $-0.036^{* *}$ \\
& $(0.017)$ \\
& \\
\hline Observaciones & 225 \\
Estadístico $\mathrm{F}$ & $13.486^{* * *}$ \\
$\mathrm{R}^{2}$-WITHIN & 0.263 \\
$\mathrm{R}^{2}$-Ajustado WITHIN & 0.126 \\
\hline \hline
\end{tabular}

Nota: entre paréntesis se encuentra el error 39 standar. Los estadísticos-t son computados usando el estimador robusto de la matriz de covarianzas de Driscoll y Kraay (1998). ${ }^{*} \mathrm{p}<0.1 ;{ }^{* *} \mathrm{p}<0.05 ;{ }^{* * *} \mathrm{p}<0.01$ 


\section{Conclusiones}

Comprender cómo los individuos forman sus opiniones respecto al desempeño económico actual y futuro puede ayudar a entender cómo estos se comportan, cómo toman decisiones y cómo influyen estas opiniones, en última instancia, en los agregados macroeconómicos y la dinámica económica. Además, desde el punto de vista de los hacedores de política económica, dicha información puede ser útil para interpretar eventos macroeconómicos de interés y anticipar el impacto que tendrán ciertas medidas de política.

En este trabajo se estudia la asociación entre las opiniones de los individuos respecto al desempeño económico y flujos de información construidos a partir de indicadores económicos de interés. Las opiniones provienen de encuestas de opinión pública realizadas a individuos de 18 países de América Latina y el Caribe para el periodo 1995-2016. Dicha encuestas son recolectadas por la ONG Latinobarómetro. En primer lugar, se estudió la asociación entre las opiniones y los flujos de información. A partir de estos ejercicios, se encontró evidencia económica y estadísticamente significativa que permite inferir que los agentes utilizan la información de indicadores económicos, objetivos y subjetivos, para formar sus opiniones respecto al desempeño económico actual y futuro. Sin embargo, cuando se analiza la fracción de la variabilidad explicada por estos indicadores, se encuentra que las variables explicativas utilizadas explican una proporción poco importante.

En segundo lugar, se propuso un modelo simple de predicción de las evaluaciones de desempeño por parte de los individuos. A partir de este modelo se encuentra que tanto las expectativas formuladas por los individuos en t como ciertos flujos de información en $\mathrm{t}-1$, contribuyen a anticipar el valor futuro de las evaluaciones de desempeño económico contemporáneas. Estos resultados, son consistente con ineficiencias en el proceso de formación de expectativas. En otras palabras, se observa que existe información relevante, al momento en que se reportan dichas expectativas, que no fue incorporada en forma adecuada. Este resultado, puede ser explicado por la presencia de individuos que poseen recursos cognitivos limitados, quienes fallan en incorporar toda la información disponible y sub-reaccionan a ciertos flujos de información. Otra fuente de ineficiencia en el proceso de formación de expectativas reportada en este trabajo, se asocia a fenómenos de sobre-reacción. En particular, se evidencia una extrapolación injustificada que se deriva de una ponderación excesiva a noticias de la prensa.

En tercer lugar, cuando este modelo simple de predicción se extiende para incorporar información sociodemográfica de los individuos, en particular, su nivel educativo y su edad, se encuentra que los resultados anteriormente mencionados se mantienen. En otras palabras, no existe evidencia estadísticamente significativa que permita inferir heterogeneidad en las creencias de los individuos. Esto último se infiere a partir de que no se encuentra ponderaciones asimétricas por parte de los individuos a los flujos entrantes de información.

Como se ha mencionado en este trabajo, los indicadores económicos utilizados tienen una pequeña capacidad explicativa sobre las medidas de opinión sobre el desempeño económico. Con el objetivo de intentar corregir dicha medida, se propuso un modelo que intenta reducir la fracción de la variabilidad de las opiniones explicada por cuestio- 
nes no vinculadas a condiciones económicas, por ejemplo, eventos políticos. En este sentido, se regresó el modelo de predicción simple prescindiendo de aquellos individuos que comunican, en el mismo conjunto de encuestas, una inclinación política fuerte. Los resultados anteriormente mencionados se mantienen, permitiéndose inferir que los mismos son robustos. Sin embargo, no se logró incrementar sustancialmente la capacidad explicativa de este modelo. Esto último, denota las dificultades asociadas a modelar la dinámica de las opiniones de los individuos.

Las direcciones en las que se puede extender este trabajo son múltiples. Por un lado, una forma de extensión involucra incorporar encuestas cuya frecuencia sea más elevada o bien, encuestas con muestras más extensas. Por otro lado, se podría desarrollar medidas más precisas de flujos de información o, bien incorporar otras. Otra alternativa se relaciona con evaluar la capacidad predictiva del indicador de expectativas, construido a partir de opiniones, sobre la evolución del PBI.

Con respecto a la primera dirección, dado que la encuesta que se utiliza en este trabajo se realiza anualmente (la cual cubre un periodo de tan solo 22 años), una muestra más grande permitirá aumentar el nivel de precisión de las mediciones y, en particular, permitirá evaluar en qué medida existe cierta regularidad en los patrones observados. Adicionalmente, se podrían incorporar otros flujos de información o mejorar la precisión de aquellos utilizados en este trabajo. Particularmente, se podría incorporar contenidos difundidos en otros medios de comunicación o construir un indicador más sofisticado respecto al indicador de opiniones en la prensa que se utiliza en este trabajo (Aromí, 2017c). 


\section{Referencias:}

Andrade, Philippe and Le Bihan, Hervé (2013). "Inattentive professional forecasters", Elsevier's Journal of Monetary Economics, 60(2013), 967-982.

Aromí, J. Daniel (2015a). "Conventional Views and Asset Prices: What to Expect after Times of Extreme Opinions?", mimeo, IIEP-Baires UBA-Conicet.

Aromí, J. Daniel (2016). "Overreactions in Economic Growth Forecasts", mimeo, IIEPBaires UBA-Conicet.

Aromí, J. Daniel (2017c). "Measuring uncertainty through word vector representations", mimeo, IIEP-Baires UBA-Conicet.

Baltagi, B.H. (2013). "Econometric Analysis of Panel Data", John Wiley y Sons, quinta edición.

Blanchard, O., \& Giavazzi, F. (2002). "Current account deficits in the euro area: the end of the Feldstein-Horioka puzzle?" Brookings papers on economic activity, 2002(2), 147209.

Beshears, J., Choi, J. J., Fuster, A., Laibson, D., \& Madrian, B. C. (2013). "What goes up must come down? Experimental evidence on intuitive forecasting" The American economic review, 103(3), 570-574.

Blinder, A. and Krueger, A. (2004). "What Does the Public Know about Economic Policy, and How Does It Know It?", National Bureau of Economic Research, NBER Working Paper No. 10787.

Brown, S. and Taylor, K. (2006). "Financial Expectations, Consumption and Saving: A Microeconomic Analysis", Fiscal Studies, 27(3), 313-338.

Calvo, G. A. (1998). Çapital ows and capital market crises: The Simple Economics of Sudden Stops". Journal of Applied Economics, 1(1), 35-54.

Carroll, Christopher (2003a). "Macroeconomic Expectations of Households and Professional Forecasters" Quarterly Journal of Economics, 118(1): 269-298.

Carroll, Christopher (2003b). "The Epidemiology of Macroeconomic Expectations", Quarterly Journal of Economics, 118(1), 269-298.

Cavallo, A., Cruces, G. and Perez-Tuglia, R. (2016). "Learning from Potentially Biased Statistics", Brookings Papers on Economic Activity, 46 (1), 59-108. 
Cavallo, A., Cruces, G. and Perez-Tuglia, R. (2017). "Inflation Expectations, Learning, and Supermarket Prices: Evidence from Survey Experiments", American Economic Journal: Macroeconomics 2017, 9(3), 1-35.

Coibion, O. and Gorodnichenko, Y. (2015). "Information rigidity and the expectations formation process: A simple framework and new facts". The American Economic Review, 105(8), 2644-2678.

Das, S., Kuhnen, C. and Nagel, S. (2017). "Socioeconomic status and macroeconomic expectations", National Bureau of Economic Research, NBER Working Paper No. 24045.

Dominitz, J. and Manski, C. (2004). "How Should We Measure Consumer Confidence?", Journal of Economic Perspectives, 18(2), 51-66.

Driscoll, J. C., Kraay, A. C. (1998). "Consistent covariance matrix estimation with spatially dependent panel data", Review of economics and statistics, 80(4), 549-560.

Edwards, S. (2004). "Thirty Years of Current Account Imbalances, Current Account Reversals, and Sudden Stops". IMF Staff Papers, 51(s1), 1-49.

Garcia, D. (2013). "Sentiment during recessions", The Journal of Finance, 68(3), 12671300.

Golub Benjamin and Jackson, O. Matthew (2010). "Naïve Learning in Social Networks and the Wisdom of Crowds". American Economic Journal: Microeconomics 2010, 2(1), 112-149.

Gorodnichenko, Y. (2008). "Endogenous Information, Menu Costs, and Inflation Persistence," NBER Working Paper 14184 (Cambridge, Massachusetts: National Bureau of Economic Research).

Heymann, D. (1994). "Sobre la interpretación de la cuenta corriente". Economía Mexicana. Nueva Época, 3(1), 31-59.

Heymann, D. y P. Pascuini (2015). "Sobre la (in)consistencia de los modelos de expectativas racionales", mimeo, IIEP-BAIRES UBA-Conicet.

Huberman, Gur, Tobias Konitzer, Masha Krupenkin, David Rothschild, and Shawndra Hill. 2018. "Economic Expectations, Voting, and Economic Decisions around Elections." AEA Papers and Proceedings, $108: 597-602$. 
Lahiri, K. and Zhao, Y. (2015). "Quantifying survey expectations: A critical review and generalization of the Carlson-Parkin method", Elsevier's International Journal of Forecasting, 31 (2015), 51-62.

Lamla, Michael J., and Sarah M. Lein. (2008). "The Role of Media for Consumers' Inflation Expectation Formation" Working Paper no. 201. Zurich: KOF Swiss Economic Institute.

Lanzilotta Mernies, B. (2015). "Expectativas empresariales: consecuencias en el crecimiento en Uruguay”, Cuadernos de Economía, 34(65), 423-442.

Leduc, S. and Sill, K. (2010). "Expectations and economic fluctuations: and analysis using survey data", Federal Reserve Bank of Philadelphia, working paper NO. 10-6.

Malmendier, U. and Nagel, S. (2013). "Learning from Ination Experiences", The Quarterly Journal of Economics, 131(1), 53-87.

Mankiw, N. and R. Reis (2002). "Sticky Information versus Sticky Prices: A Proposal to Replace the New Keynesian Phillips Curve", The Quarterly Journal of Economics, 117(4), 1295-1328.

Mankiw, N., Reis, R. and Wolfers, J. (2003). "Disagreement About Inflation Expectations", National Bureau of Economic Research, vol.18, 209-270.

Obstfeld, M., and Rogoff, K. (2007). "The unsustainable US current account position revisited. In G7 current account imbalances: Sustainability and adjustment” , 339-376, University of Chicago Press.

Reinhart, C. M., Reinhart, V. R. (2008). "Capital flow bonanzas: an encompassing view of the past and present", No. w14321, National Bureau of Economic Research.

Sachs, J. (1981). "The Current Account and Macroeconomic Adjustment in the 1970s". Brookings Papers on Economic Activity; 1(1), 201-268.

Sims, C. (2003). "Implications of rational inattention", Journal of Monetary Economics, 50(3):665-690.

Sims, C. (2010). "Rational inattention and monetary economics", Elsevier's Handbook of Monetary Policy, vol.3, 155-181.

Souleles, S. Nicholas (2004). "Expectations, Heterogeneous Forecast Errors, and Consumption: Micro Evidence from theMichigan Consumer Sentiment Surveys", Journal of Money, Credit and Banking, 36(1), 39-72. 
Tetlock, Paul, (2007). "Giving content to investor sentiment: The role of media in the stock market", Journal of Finance, 1139-68.

Woodford, M. (2001). "Imperfect common knowledge and the effects of monetary policy", National Bureau of Economic Research, working paper 8673. 


\section{Apéndice A: Ley de esperanzas iteradas en un contexto de información censura- da}

Es razonable esperar que existan importantes vínculos entre los flujos de información y la evolución de las creencias de los individuos. A priori, esta relación puede tomar diversas formas, dependiendo de cómo la información fluye y afecta las creencias. Por ejemplo, situaciones en que la evolución de las evaluaciones esperadas en $t+1$ está explicada por las expectativas formuladas en $t$, las cuales a su vez están explicadas por la llegada de información sobre fundamentales durante su proceso de formación. En estas circunstancias, la información disponible en t-1 no tendría valor predictivo sobre las evaluaciones esperadas. Esto último es consistente con los postulados que se enmarcan en los modelos FIRE (full-information rational expectations), en el cual se asume que los agentes utilizan toda la información disponible para generar un pronóstico eficiente. En este contexto:

$$
{ }_{t} y_{i t}=\alpha+\beta_{t-1} y_{i t}+\gamma I_{t-1}+\mu_{t}
$$

La creencia de los individuos $i$ en $t$ respecto a la performance económica $\left(y_{t}\right)$ será igual a la creencia que tenían dichos individuos $i$ en $t-1$ respecto a $y_{t}$. Es decir, se espera que $\beta=1, \alpha=0$ y $\gamma=0$ (asumiendo que $E_{t}\left[\mu_{t}\right]=0$ ). Si tomamos esperanza

$$
E_{i, t-1}\left[{ }_{t} y_{i t}\right]={ }_{t-1} y_{i t}
$$

Entonces, bajo FIRE se cumple la ley de esperanzas iteradas, hallándose una asociación entre lo que esperaban ayer y lo que esperan hoy respecto de la performance económica.

Sin embargo, teniendo en cuenta que en este trabajo las opiniones de los individuos son aproximadas a través de encuestas de opinión pública, dicha especificación es incorrecta, debido a que existe información censurada sobre las opiniones. En este caso:

$$
E_{t-1}\left[\operatorname{Pr}\left({ }_{t} y_{i t}>\mu\right)-\operatorname{Pr}\left({ }_{t} y_{i t}<-\mu\right)\right]=\operatorname{Pr}\left({ }_{t-1} y_{i t}>\mu\right)-\operatorname{Pr}\left({ }_{t-1} y_{i t}<-\mu\right)
$$

Bajo esta nueva especificación, las opiniones respecto a la performance económica es la diferencia entre aquellos individuos que creen que la performance económica estará mejor $\operatorname{Pr}\left({ }_{t-1} y_{i t}>\mu\right)$ menos la proporción de individuos que cree que la actividad estará peor $\operatorname{Pr}\left({ }_{t-1} y_{i t}<-\mu\right)$, siendo $\mu$ un parámetro latente fijo que define a partir de que valor la performance económica mejorará o empeorará. Además, se define un intervalo de indiferencia $(-\mu, \mu)$, en el que los individuos responderán que la variable no tendrá cambios.

Teniendo en cuenta esta especificación, se realiza un ejercicio de simulación en pos de evaluar si se mantiene la ley de esperanza iteradas bajo la presencia de información 
censurada. En pos de realizar este ejercicio, se define la opinión de cierto individuo $i$, en $t$ y $t-1$, respecto a la evolución de cierta variable, la cual puede ser caracterizada a partir de $y_{i, t-1}$ y $y_{i, t}$, respectivamente. Si suponemos la existencia una variable latente $y_{t-1}^{*}$ común para todos los individuos, podemos definir a $y_{i, t-1}=y_{t-1}^{*}+\mu_{i, t-1}$, donde $\mu_{i, t-1}$, es un término de error. A su vez, definimos $y_{i, t}=y_{i, t-1}+\pi_{i}+\varepsilon_{i, t}$, donde $\pi_{i}$ es un shock específico y $\varepsilon_{i, t}$ es un término de error. Suponemos, además, que $y^{*}, \mu, \pi$ y $\varepsilon$ siguen una distribución normal con media cero y varianza conocida. Además, se define un parámetro latente $\gamma=0,5$, a partir del cual los individuos creen que la economía mejorará o emporará. A partir de esto, se define la proporción de individuos optimistas y la proporción de individuos que cree que la economía estará peor y se computa la diferencia entre dichas proporciones para construir el indicador de opiniones.

Se realizaron dos ejercicios de simulación, cuyos resultados pueden observarse en la figura A.1 y A.2. Respecto al primero, suponiendo que la varianza de los términos $\mu$, $\pi$ y $\varepsilon$ igual a 2 , se puede concluir que la ley de esperanzas iteradas no se cumple, ya que, la relación las opiniones en $t-1 \mathrm{y} t$, no guardan una relación uno a uno (ver figura A.1). En particular, dicha relación deja de ser es lineal cuando las opiniones se alejan mucho de cero. Sin embargo, cuando se asume que la varianza de los términos es igual a 1, la relación entre las opiniones en $t-1$ y $t$, parecen guardar una relación lineal (ver figura A.2). Se puede inferir que bajo este ejercicio de simulación, la ley de esperanzas iteradas se cumple. Por lo tanto, estos resultados conllevan a cuestionar la especificación del modelo desarrollado en la sección 7. 
Figura A.1: Ley de esparanzas iteradas con información censurada: Ejercicio de simulación

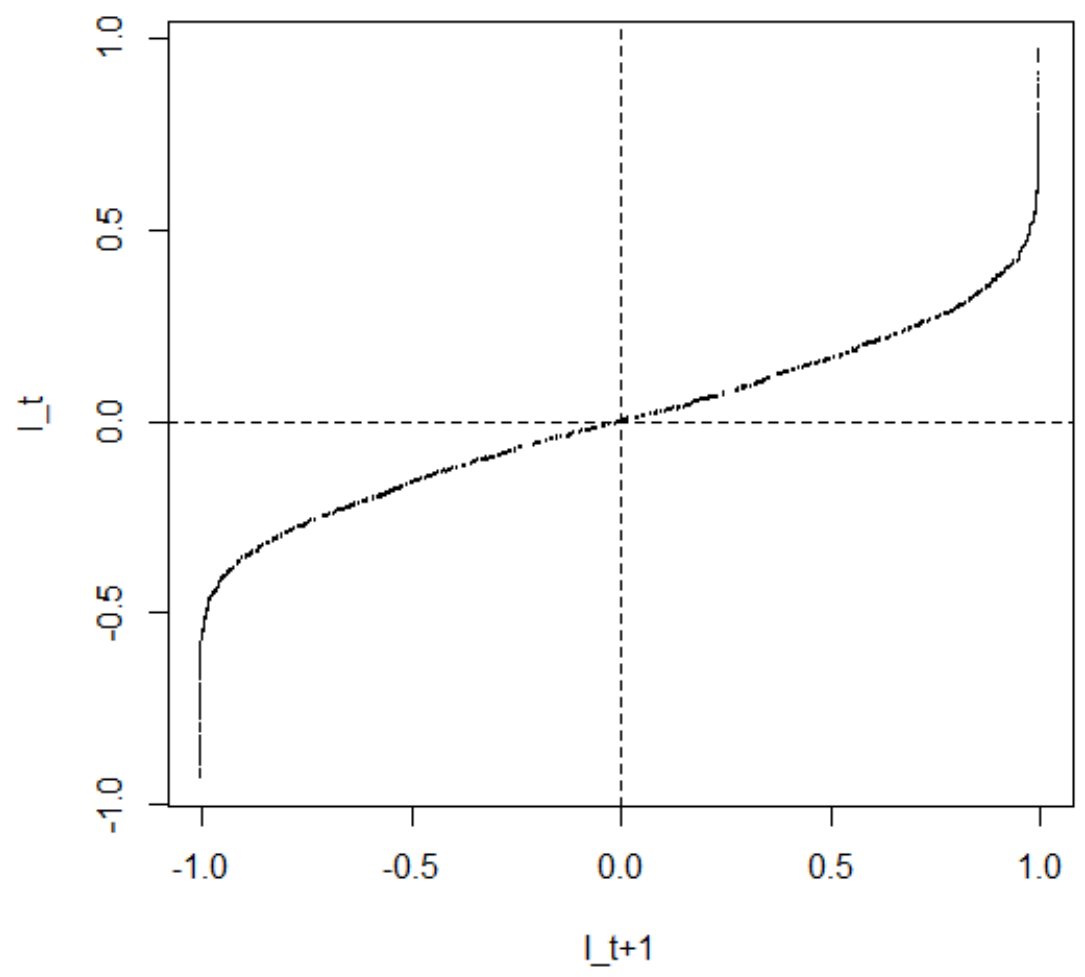


Figura A.2: Ley de esparanzas iteradas con información censurada: Ejercicio de simulación

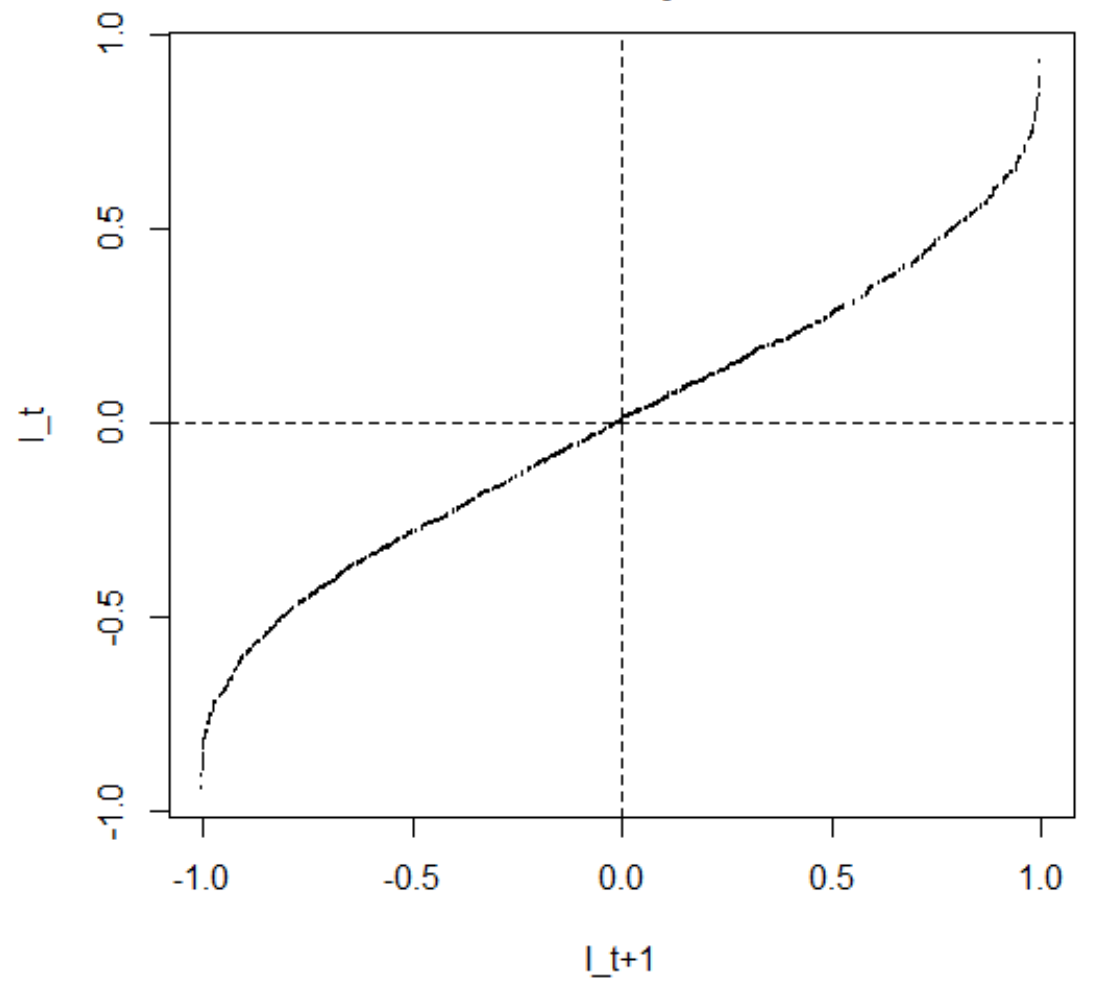

Sin embargo, como se desprende de la figura A.3, los resultados de la regresión no paramétrica de las evaluaciones esperadas en $\mathrm{t}+1$ y las expectativas formuladas por los individuos en t, permiten concluir que la especificación lineal es una aproximación adecuada. 


\section{Figura A.3: Regresión no paramétrica de la evaluación esperada de la perfomance económica}

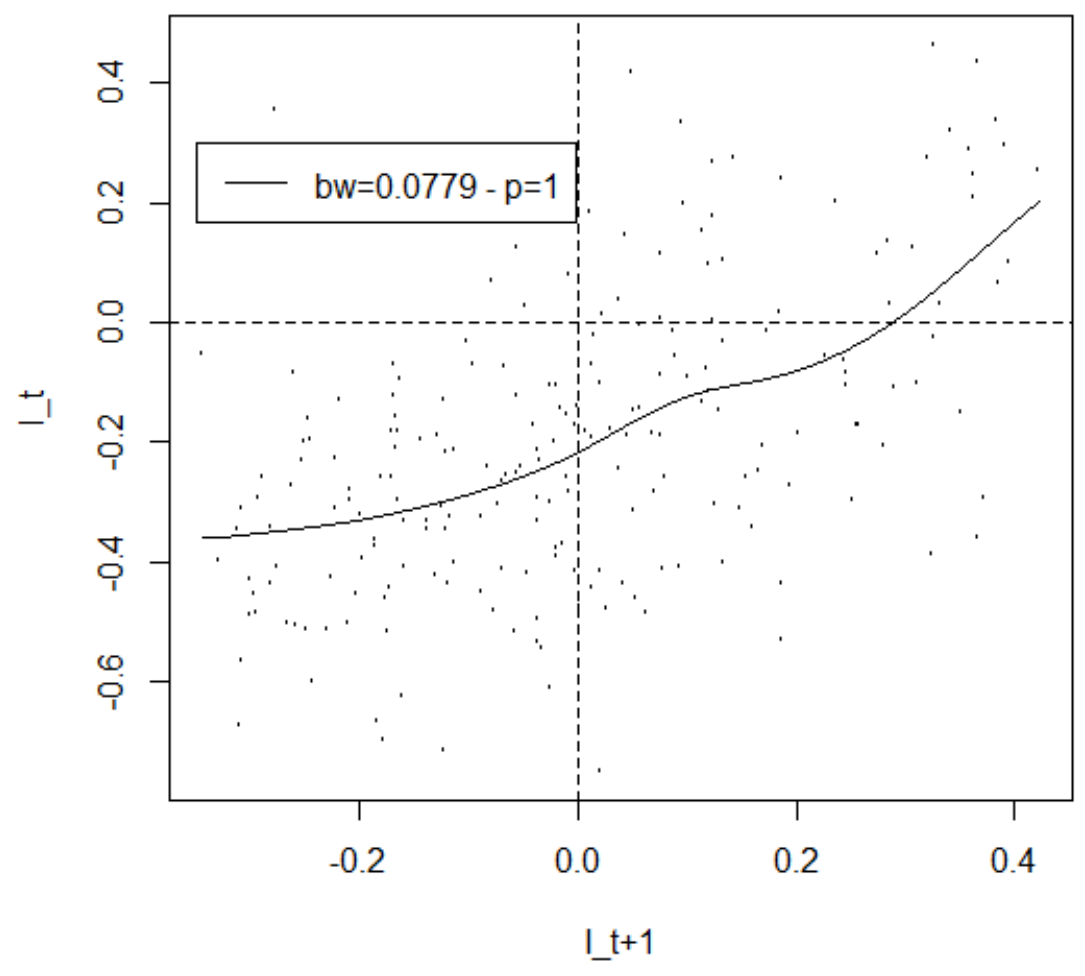

\section{Apéndice B: Indicador de opiniones sobre desempeño económico e indicador de aceleración del crecimiento.}

Este apéndice se concentra en evaluar la asociación entre el proceso de formación de opiniones y el indicador de aceleración del crecimiento. Particularmente, se analiza cómo dicha asociación responde a noticias de mediano plazo y a noticias de menor frecuencia, permitiéndose que el indicador de aceleración compare distintas ventanas de tiempo.

Teniendo en cuenta que el indicador de aceleración viene dado por $I_{[t-k, t]}^{G}=g_{[t-k, t]}-$ $g_{[t-s, t-k]}$. Este indicador compara la tasa de crecimiento anual para el período más reciente de $k$ años anteriores,donde $k \in\{1,2,3,5\}$ y la tasa de crecimiento anual para el periodo de $(s-k)$ años anteriores, con $s \in\{3,5,10,15\}$. El objetivo de este ejercicio es encontrar alguna relación entre $k$ y $s$.

A partir de analizar los coeficientes de correlación de Pearson entre la performance de crecimiento pasada teniendo en cuenta diferentes ventanas de información, se desprende que dicho coeficiente es relativamente más bajo para aquellos indicadores constituidos con información más extensa entre ellos. ${ }^{64}$ Por lo tanto, esto sugiere pre-

\footnotetext{
${ }^{64}$ El coeficiente de correlación de Pearson entre el indicador de aceleración $\beta_{k=1, s=3}$ y $\beta_{k=3, s=15}$ es 0.11 ,
} 
liminarmente que el indicador de aceleración constituido con información más distante proporciona un poder predictivo relativamente limitado para explicar la evolución del indicador de aceleración constituido para una ventana más reciente (ver tabla B.1).

Por lo tanto, un ejercicio alternativo, puede ser analizar cómo varía la asociación entre el proceso de formación de opiniones y el indicador de aceleración si este se permite incorporar un indicador de aceleración constituido con información de la performance de crecimiento pasada más reciente y otro indicador constituido para una ventana más extensa.

En la tabla B.2, se estima tanto el modelo de expectativas como el de evaluación de la performance de la economía contemporánea, teniendo en cuenta la partición del indicador de aceleración del crecimiento. Una primera observación de esta tabla permite inferir que ambas variables contribuyen a explicar la evolución del indicador de opiniones de los individuos. Esta asociación es estadísticamente significativas $1 \%$ y su relevancia económica no es depreciable. A partir de los resultados expuestos, se puede inferir que los agentes, como se concluye de la tabla B.1, forman sus expectativas y evalúan la performance económica actual asignando una mayor ponderación a la información más extensa.

\section{Apéndice C: Evaluación del contenido informativo de la información disponible sobre las evaluaciones esperadas}

Con el objetivo de otorgarle mayor sustento a algunos argumentos de la sección 7 , se estima un nuevo modelo en el cual se intenta testear si existe (o no) una asociación entre la evaluación esperada de los agente en $t+1$ y los flujos de información disponibles en $t-1$ (ver tabla C.1, columna 4). Teniendo en cuenta distintas especificaciones, se observa que sólo dos flujos de información son estadísticamente significativos. Particularmente, estos son el indicador de aceleración del crecimiento constituido para una ventana corta de tiempo y el indicador de vulnerabilidad externa (ver columna 1 a 4). Por lo tanto, sólo estos dos indicadores contribuyen a anticipar cómo los individuos evaluarán la performance economía en $t+1$ respecto a la situación económica en $t$. Estos resultados se mantienen si tenemos en cuenta la tasa de inflación y la tasa de desempleo como flujos de información observados por los agentes en $t-1$ (ver columna 6 de la tabla C.1).

Apéndice D: Evaluación del contenido informativo de las expectativas según el nivel educativo de los individuos. 
Table B.1: Asociación entre el indicador de aceleración y las opiniones de los individuos La tabla B.1 reporta los coeficientes estimados del modelo:

$$
t_{I t+z, c}=\alpha_{t}+\alpha_{c}+\beta I_{c[t-k, t]}^{G}+\mu_{c[t]}, \operatorname{con} z \in\{0,1\}
$$

La variable dependiente son las opiniones de los individuos sobre el desempeño económico pasado o futuro. Los flujos de información sólo son capturados a traves del indicador de aceleración del crecimiento constituido para distintas ventana de tiempo $(\beta)$, es decir, se permite que los parámetros que definen dichas ventanas temporales $(k$ y $s)$ tomen diferentes valores, a saber, $k \in\{1,2,3,5\}$ y $s \in\{3,5,10,15\}$.

\begin{tabular}{|c|c|c|c|c|c|c|}
\hline $\mathrm{S}$ & \multicolumn{2}{|c|}{1} & \multicolumn{2}{|c|}{2} & \multicolumn{2}{c|}{3} \\
\hline \multirow{3}{*}{3} & ${ }_{\left.{ }_{t} I_{t+1}\right]}$ & $\left.{ }_{t} I_{t}\right]$ & $\left.{ }_{t} I_{t+1}\right]$ & {$\left[{ }_{t} I_{t}\right]$} & $\left.{ }_{t} I_{t+1}\right]$ & $\left.{ }_{t} I_{t}\right]$ \\
& $0.042^{* * *}$ & $0.065^{* * *}$ & $0.056^{* * *}$ & $0.097^{* * *}$ & $0.056^{* * *}$ & $0.11^{* * *}$ \\
& $(0.011)$ & $(0.011)$ & $(0.013)$ & $(0.016)$ & $(0.013)$ & $(0.015)$ \\
5 & $0.063^{* * *}$ & $0.095^{* * *}$ & $0.068^{* * *}$ & $0.12^{* * *}$ & $0.06^{* * *}$ & $0.12^{* * *}$ \\
& $(0.009)$ & $(0.012)$ & $(0.010)$ & $(0.011)$ & $(0.013)$ & $(0.012)$ \\
10 & $0.065^{* * *}$ & $0.109^{* * *}$ & $0.068^{* * *}$ & $0.13^{* * *}$ & $0.063^{* * *}$ & $0.12^{* * *}$ \\
& $(0.009)$ & $(0.013)$ & $(0.013)$ & $(0.013)$ & $(0.015)$ & $(0.012)$ \\
15 & $0.066^{* * *}$ & $0.111^{* * *}$ & $0.068^{* * *}$ & $0.13^{* * *}$ & $0.062^{* * *}$ & $0.12^{* * *}$ \\
& $(0.009)$ & $(0.012)$ & $(0.014)$ & $(0.015)$ & $(0.015)$ & $(0.013)$ \\
& & & & & & \\
\hline
\end{tabular}

Nota: entre paréntesis se encuentra el error estandar. Los estadísticos-t son computados usando el estimador robusto de la matriz de covarianzas de Driscoll and Kraay (1998).

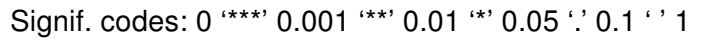


Table B.2: Asociación entre el indicador de aceleración y las opiniones de los individuos La tabla B.2 reporta los coeficientes estimados del modelo:

$$
{ }_{t} I_{t+k}=\alpha_{t}+\alpha_{c}+\beta_{G_{C}} I_{c[t-1, t]}^{G_{C}}+\beta_{G_{M}} I_{c[t-3, t]}^{G_{M}}+\mu_{c[t]}, \text { conk } \in\{0,1\}
$$

La variable dependiente son las opiniones de los individuos sobre el desempeño económico pasado o futuro. Los flujos de información sólo son capturados a traves del indicador de aceleración del crecimiento constituido para una ventana corta de tiempo $\left(\beta_{G_{C}}\right)$ y una ventana de mediano plazo $\left(\beta_{G_{M}}\right)$.

\begin{tabular}{lcc}
\hline \hline & {$\left[{ }_{t} I_{t+1}\right]$} & {$\left[{ }_{t} I_{t}\right]$} \\
\hline$\beta_{G_{C}}$ & $0.036^{* * *}$ & $0.053^{* * *}$ \\
& $(0.013)$ & $(0.014)$ \\
& & \\
$\beta_{G_{M}}$ & $0.057^{* * *}$ & $0.114^{* * *}$ \\
& $(0.016)$ & $(0.013)$ \\
& & \\
\hline Observaciones & 323 & 305 \\
Estadístico F & $16.698^{* * *}$ & $51.121^{* * *}$ \\
$R^{2}$-WITHIN & 0.105 & 0.276 \\
$R^{2}$ WITHIN-Ajustado & -0.011 & 0.179 \\
\hline \hline
\end{tabular}

Nota: entre paréntesis se encuentra el error estandar. Los estadísticos-t son computados usando el estimador robusto de la matriz de covarianzas de Driscoll and Kraay (1998). ${ }^{*} \mathrm{p}<0.1 ;{ }^{* *} \mathrm{p}<0.05 ;{ }^{* * *} \mathrm{p}<0.01$ 
Tabla C.1: Modelo descriptivo de las evaluaciones esperadas según el nivel educativo de los individuos

La tabla C.1 reporta los coeficientes estimados del modelo:

$$
{ }_{t+1} I_{t+1, c}=\alpha_{t}+\alpha_{c}+\beta_{G_{C}} I_{c[t-2, t-1]}^{G_{C}}+\beta_{G_{M}} I_{c[t-4, t-1]}^{G_{M}}+\beta_{C C} I_{c[t-1]}^{C C}+\beta_{S} I_{c[t-1]}^{S}+\mu_{c[t+1]}
$$

La variable dependiente son las evaluaciones esperadas de los individuos $\left(t+1_{I t+1}\right)$. Los flujos de información son capturados a traves del indicador de aceleración del crecimiento constituido para una ventana corta de tiempo $\left(\beta_{G_{C}}\right)$, el indicador de aceleración de mediano plazo $\left(\beta_{G_{M}}\right)$, el indicador de vulnerabilidad externa $\left(\beta_{C C}\right)$ y el indicador de sentimiento $\left(\beta_{S}\right)$. Por último, son incorparadas al análisis, la tasa de inflación $(\pi)$ y la tasa de desempleo $(\mu)$ como variables alternativas que captan las condiciones macroeconómicas.

\begin{tabular}{|c|c|c|c|c|c|c|}
\hline & [1] & [2] & [3] & {$[4]$} & [5] & [6] \\
\hline$\beta_{G_{C}}$ & $\begin{array}{c}0.046^{* * *} \\
(0.014)\end{array}$ & & & & $\begin{array}{c}0.046^{* * *} \\
(0.012)\end{array}$ & $\begin{array}{c}0.041^{* * *} \\
(0.012)\end{array}$ \\
\hline$\beta_{G_{M}}$ & & $\begin{array}{c}0.019 \\
(0.027)\end{array}$ & & & $\begin{array}{c}0.022 \\
(0.023)\end{array}$ & $\begin{array}{c}0.013 \\
(0.016)\end{array}$ \\
\hline$\beta_{C C}$ & & & $\begin{array}{c}0.082^{* * *} \\
(0.027)\end{array}$ & & $\begin{array}{c}0.076^{* * *} \\
(0.022)\end{array}$ & $\begin{array}{c}0.076^{* * *} \\
(0.018)\end{array}$ \\
\hline$\beta_{S}$ & & & & $\begin{array}{l}-0.033 \\
(0.021)\end{array}$ & $\begin{array}{c}-0.020^{*} \\
(0.011)\end{array}$ & $\begin{array}{l}-0.013 \\
(0.015)\end{array}$ \\
\hline$\mu$ & & & & & & $\begin{array}{c}0.007 \\
(0.035)\end{array}$ \\
\hline$\pi$ & & & & & & $\begin{array}{l}-0.009 \\
(0.026)\end{array}$ \\
\hline Observaciones & 298 & 298 & 299 & 284 & 283 & 256 \\
\hline Estadístico F & $10.713^{* * *}$ & 1.573 & $17.490^{* * *}$ & $2.951^{*}$ & $6.908^{* * *}$ & $3.451^{* * *}$ \\
\hline$R^{2}$-WITHIN & 0.039 & 0.006 & 0.062 & 0.012 & 0.101 & 0.087 \\
\hline$R^{2}$ WITHIN-Ajustado & -0.085 & -0.123 & -0.059 & -0.123 & -0.034 & -0.077 \\
\hline
\end{tabular}

Nota: entre paréntesis se encuentra el error estandar. Los estadísticos-t son computados usando el estimador robusto de la matriz de 5 évarianzas de Driscoll and Kraay (1998). ${ }^{*} \mathrm{p}<0.1 ;{ }^{* *} \mathrm{p}<0.05 ;{ }^{* * *} \mathrm{p}<0.01$ 
Tabla D.1: Modelo descriptivo de las evaluaciones esperadas La tabla D.1 reporta los coeficientes estimados del modelo:

${ }_{t+1} I_{t+1, c}=\alpha_{t}+\alpha_{c}+\beta_{E} P_{3[t]}+\beta_{G_{C}} I_{c[t-2, t-1]}^{G_{C}}+\beta_{G_{M}} I_{c[t-4, t-1]}^{G_{M}}+\beta_{C C} I_{c[t-1]}^{C C}+\beta_{S} I_{c[t-1]}^{S}+\mu_{c[t+1]}$

La variable dependiente son las evaluaciones esperadas de los individuos $\left(t+1_{I t+1}\right)$. Los flujos de información son capturados a traves del indicador de aceleración del crecimiento constituido para una ventana corta de tiempo $\left(\beta_{G_{C}}\right)$, el indicador de aceleración de mediano plazo $\left(\beta_{G_{M}}\right)$, el indicador de vulnerabilidad externa $\left(\beta_{C C}\right)$ y el indicador de sentimiento $\left(\beta_{S}\right)$. Ademas, las expectativas formuladas por los individuos $\left(\beta_{E}\right)$ son una variable explicativa en este modelo. Por último, son incorparadas al análisis, la tasa de inflación $(\pi)$ y la tasa de desempleo $(\mu)$ como variables alternativas que captan las condiciones macroeconómicas.

\begin{tabular}{|c|c|c|c|c|c|c|c|}
\hline & Analf. & Bas.Incomp & Bas.Comp & Sec.Incomp & Sec.Comp & Sup.Incomp & Sup.Comp \\
\hline$\beta_{E}$ & $\begin{array}{c}0.091^{* * *} \\
(0.018)\end{array}$ & $\begin{array}{c}0.087^{* * *} \\
(0.026)\end{array}$ & $\begin{array}{c}0.090^{* * *} \\
(0.027)\end{array}$ & $\begin{array}{c}0.109^{* * *} \\
(0.022)\end{array}$ & $\begin{array}{c}0.104^{* * *} \\
(0.025)\end{array}$ & $\begin{array}{c}0.082^{* * *} \\
(0.022)\end{array}$ & $\begin{array}{c}0.084^{* * *} \\
(0.018)\end{array}$ \\
\hline$\beta_{G_{C}}$ & $\begin{array}{c}0.033^{* *} \\
(0.013)\end{array}$ & $\begin{array}{l}0.032^{* *} \\
(0.013)\end{array}$ & $\begin{array}{l}0.032^{* *} \\
(0.013)\end{array}$ & $\begin{array}{l}0.028^{* *} \\
(0.011)\end{array}$ & $\begin{array}{l}0.031^{* *} \\
(0.013)\end{array}$ & $\begin{array}{c}0.035^{* * *} \\
(0.013)\end{array}$ & $\begin{array}{c}0.038^{* * *} \\
(0.013)\end{array}$ \\
\hline$\beta_{G_{M}}$ & $\begin{array}{c}0.010 \\
(0.023)\end{array}$ & $\begin{array}{c}0.005 \\
(0.023)\end{array}$ & $\begin{array}{c}0.011 \\
(0.023)\end{array}$ & $\begin{array}{c}0.004 \\
(0.011)\end{array}$ & $\begin{array}{c}0.004 \\
(0.022)\end{array}$ & $\begin{array}{c}0.010 \\
(0.024)\end{array}$ & $\begin{array}{c}0.019 \\
(0.023)\end{array}$ \\
\hline$\beta_{C C}$ & $\begin{array}{c}0.056^{* * *} \\
(0.018)\end{array}$ & $\begin{array}{c}0.052^{* * *} \\
(0.018)\end{array}$ & $\begin{array}{c}0.057^{* * *} \\
(0.018)\end{array}$ & $\begin{array}{c}0.054^{* * *} \\
(0.018)\end{array}$ & $\begin{array}{c}0.052^{* * *} \\
(0.017)\end{array}$ & $\begin{array}{c}0.063^{* * *} \\
(0.021)\end{array}$ & $\begin{array}{c}0.067^{* * *} \\
(0.020)\end{array}$ \\
\hline$\beta_{S}$ & $\begin{array}{c}-0.032 \\
(0.021)\end{array}$ & $\begin{array}{c}-0.036^{*} \\
(0.021)\end{array}$ & $\begin{array}{c}-0.037^{*} \\
(0.019)\end{array}$ & $\begin{array}{l}-0.029 \\
(0.019)\end{array}$ & $\begin{array}{c}-0.036^{* *} \\
(0.016)\end{array}$ & $\begin{array}{c}-0.037^{* *} \\
(0.019)\end{array}$ & $\begin{array}{c}-0.037^{* *} \\
(0.018)\end{array}$ \\
\hline Observations & 224 & 225 & 225 & 225 & 225 & 225 & 225 \\
\hline $\mathrm{R}^{2}$ & 0.231 & 0.216 & 0.221 & 0.260 & 0.260 & 0.208 & 0.240 \\
\hline Adjusted $\mathrm{R}^{2}$ & 0.088 & 0.071 & 0.076 & 0.123 & 0.123 & 0.062 & 0.099 \\
\hline F Statistic & $11.317^{* * *}$ & $10.421^{* * *}$ & $10.701^{* * *}$ & $13.283^{* * *}$ & $13.258^{* * *}$ & $9.943^{* * *}$ & $11.929^{* * *}$ \\
\hline
\end{tabular}

Nota: entre paréntesis se encuentra el error estandar. Los estadísticos-t son computados usando el estimador robusto de la matriz de covarianzas de Driscoll and Kraay (1998).

${ }^{*} \mathrm{p}<0.1 ;{ }^{* *} \mathrm{p}<0.05 ;{ }^{* * *} \mathrm{p}<0.01$ 